\title{
Spatial modeling could not differentiate early SARS-CoV-2 cases from the distribution of humans on the basis of climate in the United States
}

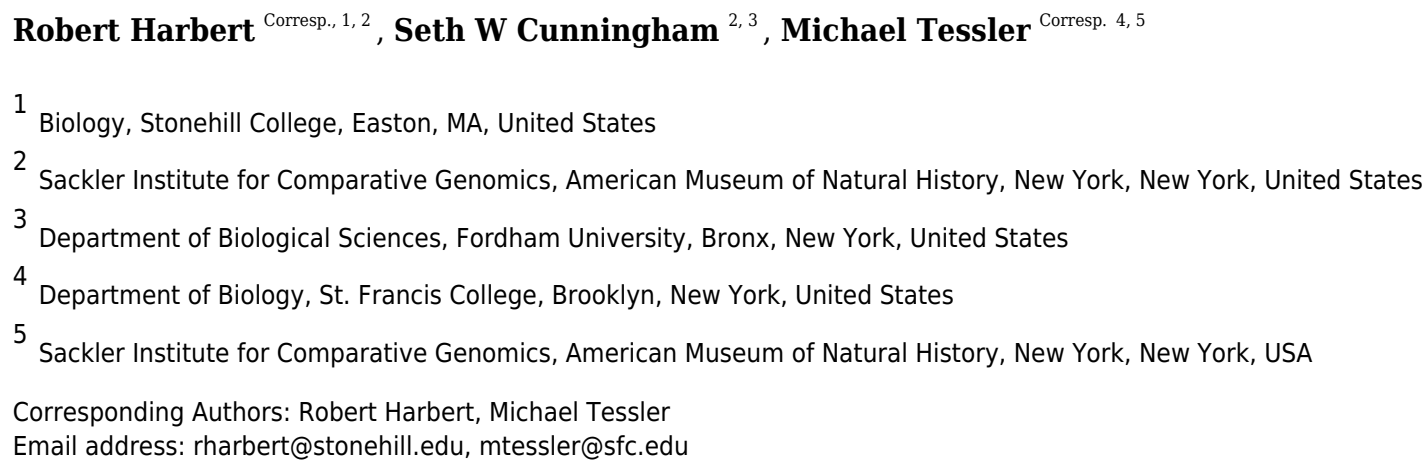

The SARS-CoV-2 coronavirus is wreaking havoc globally, yet, as a novel pathogen, knowledge of its biology is still emerging. Climate and seasonality influence the distributions of many diseases, and studies suggest at least some link between SARSCoV-2 and weather. One such study, building species distribution models (SDMs), predicted SARS-CoV-2 risk may remain concentrated in the Northern Hemisphere, shifting northward in summer months. Others have highlighted issues with SARS-CoV-2 SDMs, notably: the primary niche of the virus is the host it infects, climate may be a weak distributional predictor, global prevalence data have issues, and the virus is not in population equilibrium. While these issues should be considered, we believe climate's relationship with SARS-CoV-2 is still worth exploring, as it may have some impact on the distribution of cases. To further examine if there is a link to climate, we build model projections with raw SARS-CoV-2 case data and population-scaled case data in the United States. The case data were from across March 2020, before large travel restrictions and public health policies were impacting cases across the country. We show that SDMs built from population-scaled case data cannot be distinguished from control models (built from raw human population data), while SDMs built on raw case data fail to predict the known distribution of cases in the U.S. from March. The population-scaled analyses indicate that climate did not play a central role in early U.S. viral distribution and that human population density was likely the primary driver. We do find slightly more population-scaled viral cases in cooler areas. Ultimately, the temporal and geographic constraints on this study mean that we cannot rule out climate as a partial driver of the SARS-CoV-2 distribution. Climate's role on SARS-CoV-2 should continue to be cautiously examined, but at this time 
we should assume that SARS-CoV-2 will continue to spread anywhere in the U.S. where governmental policy does not prevent spread. 
1 Spatial modeling could not differentiate early SARS-CoV-2 cases from the distribution of

2 humans on the basis of climate in the United States

3

4 Robert Harbert ${ }^{1,2,{ }^{*} \text {, Seth W. Cunningham }}{ }^{2,3}$, and Michael Tessler 2,4 ,

51 Stonehill College, Easton, Massachusetts

62 Sackler Institute for Comparative Genomics, American Museum of Natural History, New York,

7 New York

$8{ }^{3}$ Department of Biological Sciences, Fordham University, Bronx, New York

$9{ }^{4}$ Department of Biology, St. Francis College, Brooklyn, New York

10

$11{ }^{*}$ Co-corresponding authors:

12

13 Robert Harbert

14 Stonehill College, Easton, MA 02780

15 rharbert@stonehill.edu;

16

17

Michael Tessler

18

St. Francis College, Brooklyn, NY 11201

19

mtessler@sfc.edu

20

\section{Abstract}

The SARS-CoV-2 coronavirus is wreaking havoc globally, yet, as a novel pathogen, knowledge of its biology is still emerging. Climate and seasonality influence the distributions of many diseases, and studies suggest at least some link between SARS-CoV-2 and weather. One such study, building species distribution models (SDMs), predicted SARS-CoV-2 risk may remain concentrated in the Northern Hemisphere, shifting northward in summer months. Others have highlighted issues with SARS-CoV-2 SDMs, notably: the primary niche of the virus is the host it infects, climate may be a weak distributional predictor, global prevalence data have issues, and the virus is not in population equilibrium. While these issues should be considered, we believe climate's relationship with SARS-CoV-2 is still worth exploring, as it may have some impact on the distribution of cases. To further examine if there is a link to climate, we build model projections with raw SARS-CoV-2 case data and population-scaled case data in the United

33 States. The case data were from across March 2020, before large travel restrictions and public 34 health policies were impacting cases across the country. We show that SDMs built from 
35 population-scaled case data cannot be distinguished from control models (built from raw human 36 population data), while SDMs built on raw case data fail to predict the known distribution of 37 cases in the U.S. from March. The population-scaled analyses indicate that climate did not play 38 a central role in early U.S. viral distribution and that human population density was likely the 39 primary driver. We do find slightly more population-scaled viral cases in cooler areas. Ultimately, 40 the temporal and geographic constraints on this study mean that we cannot rule out climate as a 41 partial driver of the SARS-CoV-2 distribution. Climate's role on SARS-CoV-2 should continue to 42 be cautiously examined, but at this time we should assume that SARS-CoV-2 will continue to 43 spread anywhere in the U.S. where governmental policy does not prevent spread.

44

45 Keywords: climate, coronavirus, COVID-19, SARS-CoV-2, species distribution modeling, 46 United States 


\section{Introduction}

\section{SARS-CoV-2 and climate overview}

In March 2020, the United States of America had the most reported cases of COVID-19, the disease caused by the coronavirus SARS-CoV-2 (CDC NCIRD 2020). While we are now beginning to understand the global and US-level distributions of this virus, we are only starting to learn how abiotic variables affected its geographic distribution, particularly before policy seemed to become the principal driver of the virus. With over two months of SARS-CoV-2 records across U.S. counties by the end of March 2020, the role of abiotic variables had become easier to examine, especially as multiple sources began compiling data and making it public (The New York Times 2020; Dong, Du, and Gardner 2020; The COVID Tracking Project 2020).

8
interactions with biotic and abiotic variables (Elith and Leathwick 2009) - SARS-CoV-2 is no exception. As this virus is primarily distributed by human hosts, it is constrained by human distributions and interactions (i.e., biotic variables). There are numerous documented cases on local and global scales of individual human sources for new outbreaks (Holshue et al. 2020; KCDC 2020). Still, many other viruses, including other coronaviruses, display marked seasonality and are affected by local climatic conditions (Price, Graham, and Ramalingam 2019; Fisman 2012; Lofgren et al. 2007; Gaunt et al. 2010). This has prompted researchers to begin looking globally at how weather and climate (i.e., a subset of abiotic variables) may relate to the presence and abundance of the virus.

Modeling the SARS-CoV-2 viral distribution from the early part of the outbreak in relation to climate and other abiotic variables could help refine our understanding of its spread, hopefully adding to the knowledge gleaned from studies on human transmission dynamics (Kucharski et al. 2020; Chinazzi et al. 2020), which appears to explain much of the viral distribution. Climate can also be compared directly to biotic variables, such as human population density, to disentangle their relative importances. More dense human populations can have elevated communicable disease spread, as there is more person-to-person contact (Fang et al. 2013) the principal way SARS-CoV-2 is known to spread (Rothan and Byrareddy 2020). Still, identification of abiotic variables with suitably large effect size on the distribution and spread of SARS-CoV-2 might help prevent viral spread by identifying higher-risk regions and projecting seasonal variation in the risk of transmission. However, it is important to make clear that the models presented here, and in other recent studies (Araújo and Naimi 2020; Bariotakis et al. 2020), are influenced by the variability of input parameters, the variables explored, and the 
81 restrictions inherent in modeling any complex system (Elith et al. 2011). We present this study

82 to serve as a baseline in our understanding, given the available data, rather than as a definitive 83 model.

84

\section{SARS-CoV-2 and climate research}

Early studies suggest that transmission of SARS-CoV-2 may have, at a minimum, a loose association with climatic features. There have been numerous reports showing a correlation of case incidence with cool temperatures and low humidity (Wang et al. 2020; Ficetola and Rubolini 2020; Bannister-Tyrrell et al. 2020; Araújo and Naimi 2020; Chen et al. 2020; Alvarez-Ramirez and Meraz 2020; Notari 2020; Paez et al. 2020). Furthermore, studies that controlled for case growth rate or demographic factors found that weather was still a significant factor in the success of SARS-CoV-2 outbreaks (Bukhari and Jameel 2020; Chen et al. 2020; Sajadi et al. 2020). Unfortunately, none of these studies provide a mechanism for how abiotic variables like temperature might limit or promote the person-to-person transmission of the virus. Still, lipid-enveloped viruses (including coronaviruses) may be more stable outside of the host in lower humidity and cooler temperatures, conditions that are common in temperate areas in late winter and early spring (Price, Graham, and Ramalingam 2019). Recent studies have also indicated that SARS-CoV-2 transmission rate may be negatively correlated with temperature and humidity (Qi et al. 2020; Wu et al. 2020; Rosario et al. 2020; Ahmadi et al. 2020)(Sagripanti and David Lytle 2020). However, the mechanism causing these correlations could be indirect, as humans behave differently in different seasons (Bedford et al. 2015; Wesolowski et al. 2017). Recent epidemiological models have also highlighted that weather may not play a large role when most people lack immunity during the pandemic phase but indicate that weather has the potential to play a larger role once the endemic phase is reached (Baker et al. 2020).

Biologists often employ species distribution models (SDMs; alternatively called ecological niche models) to predict geographic ranges of species. SDMs employ environmental data (typically climate) to predict if geographic space is suitable for a given species or population (Peterson 2001; Peterson et al. 2011). These models have proven useful in a wide variety of applications, such as invasion biology, climate change, zoonotic diseases, and

112 spread of viral pathogens often do so by modeling the potential distribution of known vectors or 113 alternate hosts (R. H. Miller et al. 2012; Larson et al. 2010; de Almeida et al. 2019; Richman et 114 al. 2018), but some base the models directly on pathogen occurrence data (Machado-Machado 
115 2012; Belkhiria, Alkhamis, and Martínez-López 2016; Pigott, Bhatt, et al. 2014; Messina et al.

116 2015; Bhatt et al. 2013). Efforts to model global disease distribution within an ecological

117 framework frequently draw on known or hypothesized environmental variables correlated with

118 disease occurrence to predict suitability for transmission. Output from these models can be

119 extrapolated into areas where a disease has not yet been reported, but where suitable

120 environmental variables correlated with its occurrence exist (Elith and Leathwick 2009).

121 Researchers early in the pandemic created SDMs of SARS-CoV-2 using climatic

122 variables (Araújo and Naimi 2020; Bariotakis et al. 2020). These studies suggested that the

123 virus is strongly constrained by global climate patterns (Araújo and Naimi 2020; Bariotakis et al.

124 2020). Preliminary models also suggested that the virus would continue to be concentrated in

125 the Northern Hemisphere, shifting northwards throughout the summer and then back towards its

126 spring distribution in the fall and winter (Araújo and Naimi 2020).

127 However, a research group put forth a strong rebuttal (Chipperfield et al. 2020) to some

128 of this modeling work (Araújo and Naimi 2020). Their main criticism asserts that basic

129 assumptions underlying SDMs are violated when modeling SARS-CoV-2, due to the mode of

130 transmission, current population disequilibrium, and failure to incorporate epidemiological data

131 (Chipperfield et al. 2020). Furthermore, they highlight issues pertaining to input data for global

132 records, such as: missing data, omitted data, and single localities representing many thousands

133 of reported cases (hospital coordinates or political centroids) across an entire country (Araújo

134 and Naimi 2020). This is exacerbated as many countries are reporting records based on varied

135 criteria, such as multiple types of molecular tests and tests using computed tomography scans

136 (Lippi, Simundic, and Plebani 2020). The rebuttal additionally suggested that model evaluation

137 and justification were insufficient. An updated draft of the original paper (Araújo and Naimi 2020)

138 addressed some of these issues, and produced reasonable arguments to some others. While

139 we agree with many arguments from the rebuttal, we believe SDMs have the potential to be

140 useful for modeling in a number of instances, if done carefully, and have been effective when

141 used for other diseases (Pigott, Golding, et al. 2014; Pigott et al. 2015; Carlson, Dougherty, and

142 Getz 2016) and other instances when data are limited or incomplete (Galante et al. 2018;

143 Barbet-Massin et al. 2018; Katz and Zellmer 2018; Pearson et al. 2006; Fois et al. 2018;

144 Hernandez et al. 2006; Kiedrzyński et al. 2017).

145 Still, the climate-based SDMs for SARS-CoV-2 presented recently may, to at least some

146 extent, reflect the climatic preferences of their host. Careful consideration of host availability

147 (human population density) and pathogen ecologies (abiotic variables related to transmission)

148 may be necessary to frame analyses modeling the global distribution (Johnson, Escobar, and 
149 Zambrana-Torrelio 2019), and may help to better ensure that projected distributions are not

150 simply the result of environmental variables related to human population density.

151

\section{SARS-CoV-2 in the US}

COVID-19 was first detected in the U.S. on January 20, 2020 (Holshue et al. 2020), has since been detected in all 50 states, and continues to spread rapidly (Chinazzi et al. 2020). Quality county-level data are also publically available (The New York Times 2020; The COVID Tracking Project 2020; Dong, Du, and Gardner 2020). As of July 22, 2020, SARS-CoV-2 has caused just under 145,000 deaths in the U.S. (IHME COVID-19 team and Murray 2020). However, like much of the world, the case distribution is rapidly changing, and the case numbers continue to rise and fall. Public policy decisions appear to be the main mitigating factor against this coronavirus (Leonhardt 2020).

Here we develop a suite of data visualizations, species distribution models, and comparative niche overlap analyses using both climate and human population data to determine whether the effect of climate can be appropriately disentangled from other drivers of SARSCoV-2 transmission, given early records for the virus in the U.S. We feel that examining a relatively early time-point of the pandemic in the U.S. is useful, as it in part (probably largely) predates the impact of major shifts in public health policy for the U.S.

167

168

\section{Materials \& Methods}

\section{Code and results deposition}

The code and results developed in this study are deposited under a CC-BY-NC 4.0 License on Github (https://github.com/rsh249/cv19 enm/releases/tag/v0.0.5). All analysis code was written using R 3.6.2 (R Core Team 2019). Plots for Figures 1, 2, 3, S1, and S2 were produced using the "ggplot2" package (Wickham 2009).

\section{Data acquisition}

SARS-CoV-2 case data for U.S. counties (one record per county, with a total sample size of 1,883 counties that had available reports) were collected from the New York Times database (The New York Times 2020) on March 31, 2020, for the March 30, 2020 data release. County-level data on human population densities were acquired from the 2010 United States

180 Census through the R "tidycensus" package (Walker, Eberwein, and Herman 2020).

181 Georeferencing to county centroids was performed by referencing county and state names in 182 the GeoNames database (https://www.geonames.org/). While exact virus case geolocations or 
183

184

185

186

187

188

189

190

191

192

193

194

195

196

197

198

199

200

201

202

203

204

205

206

207

208

209

210

211

212

213

214

215

216

even town-level data would provide finer scale resolution to our analyses, these data are likely the best curated dataset for the U.S. for this time period.

\section{Climate data}

Interpolated climate data averaged from 1970-2000 for the month of March were accessed through the WorldClim v2.1 database (Fick and Hijmans 2017). The seven climate parameters examined for the month of March were average monthly temperature, average monthly minimum temperature, average monthly maximum temperature, average monthly precipitation, average daily solar radiation, wind speed, and water vapor pressure (a measure related to humidity). These climate parameters are consistent with possible correlates of SARSCoV-2 transmission in several recent studies (Qi et al. 2020; Sagripanti and David Lytle 2020; Ahmadi et al. 2020; Rosario et al. 2020; Wu et al. 2020). Climate data were extracted from these layers for each georeferenced county record using the average from a $5 \mathrm{~km}$ buffer around each county centroid coordinate. These local averages should represent the county generally as climate is correlated over short distances, but these averages may not be the best representation in counties that have a large area or highly clustered population centers. While county centroids may not be ideal in all circumstances, our view is that county centroids plus this buffer will average the climate relative to most cases in the area. More precise case georeferencing is not possible without high levels of individual case and movement tracking to identify the source of infection.

\section{Climate Distribution Visualization}

Total cumulative positive case data for SARS-CoV-2 in each reporting county on March 30,2020 , were used to extract data for the seven abiotic variables listed above. Probability density distributions for SARS-CoV-2 were produced to characterize the likelihood of case occurrence given the available range of climate values. These distributions are calculated from case occurrences and corresponding climate data using a Gaussian Kernel Density Estimator and standard bandwidth estimation. These distributions can be interpreted similarly to histograms, but are normalized to be comparable between different sample sizes. Raw case data (i.e., total cases per county) were scaled to reflect virus cases in each county unit by dividing total cases by the county population from the 2010 U.S. Census. These populationscaled viral cases (cases / population) were used as probability density weightings, and resulting curves were standardized to an area of one. Probability densities were also calculated with raw case count data and county-level population as weightings. Probability density 
217 estimation and visualization was done with the $R$ 'ggplot2' package (Wickham 2009). To test

218 whether the SARS-CoV-2 cases and human population data were correlated, we applied

219 Spearman tests "cor.test(method=' spearman')".

220

221

\section{Species distribution models}

222

Occurrence data for raw (i.e., total viral cases) SDMs were generated by expanding

223 each county climate record by multiplying that occurrence by the total SARS-CoV-2 case count for each county. Occurrence data for population-scaled SDMs were generated the same way as for the raw SDMs except that county climate records were multiplied by the total case count divided by the county population. Then population-scaled values were multiplied by an expansion factor of 100,000 so that all counties with at least one case were represented. More explicitly: raw data = total viral cases; population-scaled data $=$ total viral cases $/$ human population $\times 100,000$ (the expansion factor for our data). Viral host availability (i.e., total humans per county) was modeled to serve as a null distribution to be used as a control comparison for viral SDMs.

Maxent, an algorithm for presence-only distribution models (Elith et al. 2011), parameters relating to model complexity were tested by building a suite of SDMs for SARSCoV-2 distribution data with occurrences generated from raw reported virus case values and population-scaled case values. Maxent model testing and cross validation was performed using the ENMeval package (Muscarella et al. 2014) considering linear and quadratic feature classes (constraints on model fit) and regularization multipliers (penalties on complexity) of $0.5,1,1.5,2$, calculated with cross validation using the spatial 'block' partitioning method, and minimizing AICc in the case of ties.. All models were built using the Maxent algorithm implemented in the "maxnet" R package (Phillips 2017), including those tested within ENMeval. Operational models using the optimal model parameters were then built for SARS-CoV-2 using all population-scaled data, raw virus data, and for the human population using the county population data (Phillips 2017). Of the seven WorldClim variables, the three temperature variables are not independent. Accordingly, we only used maximum temperature, as higher temperatures have been hypothesized to lower the viral distribution. Models built using all temperature variables made

247 similar models, but are not further reported on. Reducing correlated variables is generally 248 preferable to avoid extrapolation issues that arise from local covariance between variables 249 (Araújo et al. 2019a). 
Given recent critiques, it has become clear that when using SDMs in relation to SARS-

251

252

253

254

255

256

257

258

259

260

261

262

263

264

265

266

267

268

269

270

271

272

273

274

275

276

277

278

279

280

281

282

283

CoV-2, it is worth documenting how close a study may come to the gold standards set for this type of modeling (Araújo et al. 2019b). The mode rank for our SDMs is bronze (Table 1), largely as data from an emerging disease are inherently imperfect. Our SDMs rely on incomplete (limited or underreported data) observational data that reports only positive tests for the continental United States. The SDMs also only model over climate averages for the month of March (averaged from 1970-2000), which may result in a truncated climate envelope. However, despite imperfect data the SDMs reported here fulfill the silver or gold standard methodology for model complexity, treatment of bias, and model evaluation (Table 1).

Niche overlap and similarity tests were conducted with the "ecospat" library (Di Cola et al. 2017; Broennimann et al. 2012; Warren, Glor, and Turelli 2008) to compare the climatic niche of SARS-CoV-2 and humans. The niche overlap test considers whether there is a greater than expected overlap between the climate space occupied by two population models (human total vs. SARS-CoV-2 positive) than would be expected given a null distribution sampled from both populations. The niche similarity test considers the degree of similarity between the density of occurrence between two population models relative to the same null distribution (Warren, Glor, and Turelli 2008). A significant overlap between SARS-CoV-2 and total human population models indicates that the virus' distribution is not necessarily constrained by climate (i.e., that the full range of human occupied climate is accessible to the virus).

\section{Results}

\section{Climate Distribution Visualizations}

The human population climate curves are visually similar compared to the populationscaled SARS-CoV-2 climate curves for all seven abiotic variables for March 30 (Figure 1). There do appear to be modest differences in the population-scaled viral curves towards cooler temperatures and lower water vapor pressure compared to the human population curves. The raw density of SARS-CoV-2 cases (Figure S1) is visually different from the population-scaled data (Figure 1). Population-scaled SARS-CoV-2 data appear to become better fitted to the human population data over time (i.e., these curves better match on March 30 than they did on March 2 or 16, 2020; Figure 1), whereas the raw SARS-CoV-2 case data become more and more fixed on a narrow range of values for all climate variables (Figure S1). The latter (fixed and narrow) range presumably has to do with a few virus hotspots.

There is a highly significant positive relationship (Spearman's $r=0.75, p<2 \mathrm{e}^{-12}$ ); between the number of humans in a county and the number of viral cases; however, the 
284 population-scaled viral cases do not have a strong relationship (Spearman's $r=0.05, p=0.03$ ) 285 with human populations (Figure 2). Although the latter $p$-value is significant, this is often not all 286 that meaningful for large datasets, whereas the weak $r$ value better illustrates the relationship 287 for the population-scaled data.

288

289

290

291

292

\section{Species distribution models}

Model testing for SARS-CoV-2 population-scaled case model identified a Maxent model with linear and quadratic feature classes and a regularization multiplier of 0.5 as the best model, with a reasonably high model fit and transferability under block resampling (Avg. Test AUC = 0.82; Test AUC variance $=0.0002$ ). Population-scaled case and human population models built using these optimal model parameters appear to be highly similar, with areas of high suitability predicted for much of the West Coast and most of the eastern half of the U.S. (Figure 3). There are some differences; for instance, the population-scaled model output for SARS-CoV-2 (Figure $3 \mathrm{~A}$ ) suggests Florida is less suitable than it is in the map for human population (Figure 3B).

Model testing for the SARS-CoV-2 raw case dataset identified a Maxent model with linear and quadratic feature classes and a regularization multiplier of 1.5 as the optimal model with a high model fit (Avg. Test AUC $=0.88$ ), but with a slightly lower model transferability evidenced by higher AUC variance (Test AUC variance $=0.007$ ) than the population-scaled model. The SDMs of the raw virus cases (Figure S2) fail to reconstruct the known distribution of

303 viral cases in much of the U.S. with strong bias towards the Pacific Northwest and Northeastern

304 United States. The SDMs for humans (Figure 3, S2) do not exactly match current human distribution for the U.S. However, this was expected, because the goal of the model is to match climates that are correlated with the places where most people live (i.e., it is not simply a map of current human populations). We did this as our ultimate goal was comparing a viral model to a human model.

The niche overlap and similarity tests both find that the models of SARS-CoV-2 (population-scaled viral case data) and human population have significantly higher overlap $(p<$ 0.01 ) than would be expected by chance (Figure 4), confirming the visual similarities between

312 these maps. The raw data showed less overlap: the similarity test was significant, but an order of magnitude less so than for the population-scaled data $(p=0.02)$, while the overlap test was insignificant $(p=0.20)$, as seen in Figure $\mathbf{S 3}$.

\section{Discussion}

\section{Main findings}


318

319

320

321

322

323

324

325

326

327

328

329

330

331

332

333

334

335

336

337

338

339

340

341

342

343

344

345

346

347

348

349

350

Our results suggest that population-scaled SARS-CoV-2 coronavirus cases from March 2020 were highly linked with the human populations in the U.S. and that any influence of climate is hard to disentangle for SARS-CoV-2 cases for the U.S. during this time period (Figures 1-4). Furthermore, this link was strengthening over the duration of March (Figure 1). This indicates that caution should be used when dealing with climate modeling of SARS-CoV-2, at least on a national scale. Our results, while broadly similar to what was found in the U.S. for global-scale models (Araújo and Naimi 2020; Bariotakis et al. 2020), indicate that the pattern we observed is simply reflecting human population density. Based on this, at least human population density should be compared or incorporated in any modeling exercises for SARS-CoV-2. Accordingly, the current global results from other studies (Araújo and Naimi 2020; Bariotakis et al. 2020) should not be taken at face value without a critical comparison to human distributions. Furthermore, this is in line with current knowledge that public policy is the main driver for coronavirus spread in the U.S. (Leonhardt 2020). It is also in line with modeling efforts that have combined epidemiological variables with climate (Baker et al. 2020).

It is also noteworthy that our models using the raw viral case data (Figure S2), as opposed to population-scaled data (Figure 3), performed poorly: the raw SDMs did not highlight most of the known March range of SARS-CoV-2 in the U.S. Other distribution modeling studies have only used raw values as inputs (Araújo and Naimi 2020; Bariotakis et al. 2020), which our model shows to be at risk of overfitting and low model transferability to novel regions. Similarly, our analysis of raw SARS-CoV-2 case data shows that over time the probability density curves focus on a narrower range of climate as more data comes from the areas most affected by the outbreak (Figure S1). In contrast, adjusting for population size with the population scaling results in SARS-CoV-2 climate curves more closely approaching that of the human population curves over time (Figure 1). Furthermore, county-level human population numbers only appear to be strongly correlated with raw cases, rather than population-scaled cases (Figure 2). Together these observations suggest that the SARS-CoV-2 was highly successful in a few areas in March (e.g., New York City), but when scaled for the available human population in each county we can infer a much broader geographic and climatic range was available.

Again, our data provide a few indications that climate may have had some relevance for SARS-CoV-2 distributions in March. Viral probability densities were slightly higher in cooler locales (Figure 1, S1). The population-scaled data were particularly compelling, even if the climate difference is smaller, as they are less driven by the current SARS-CoV-2 hotspots. Furthermore, our population-scaled viral SDMs, while statistically indistinguishable from our 
351 human SDMs, had lower suitability for the virus in Florida and the southwestern border (Figure

352 3). Whereas in reality, Florida had $>5000$ cases in March.

353

354

355

356

357

358

359

360

361

362

363

364

365

366

367

368

369

370

371

372

373

374

375

376

377

378

379

380

381

382

383

384

\section{Avoiding a presumably faulty prediction}

Given that our SDMs for humans and the virus had significant niche overlap and similarity (Figure 4), we do not believe that a future projection of our SARS-CoV-2 SDMs in the U.S. using only climate data would be trustworthy at this point in time, and therefore we do not present one. A model based on March data would likely have suggested the SARS-CoV-2 prevalence would have shifted northward during the summer, which would be congruent with another early global modeling study (Araújo and Naimi 2020). However, given that humans do not move northward in large numbers in the U.S. during the summer, our predictions would be based on faulty presumptions about host resources (i.e., that there are sufficient humans in the north to harbor the bulk of cases). Most importantly, we now know that the virus has spread across much of the southern U.S. during the summer. One could imagine this counterintuitive spread was, in addition to inadequate public health policy, due in part to people in the southern states staying indoors more in the summer, replicating the behavior found in the northern states during the winter. Still, it is possible that a future model projection would turn out to be correct using updated datasets, and there could be at least some residual predictive power that is not fully encompassed by human population patterns.

\section{Modeling counterarguments}

It has now been argued that SDMs of SARS-CoV-2 can help to predict where the virus may generally be found now and in the future (Araújo and Naimi 2020; Bariotakis et al. 2020), as well as why it might be a fool's errand to conduct these analyses in the first place (Chipperfield et al. 2020). Here are some of the main arguments that have been put forward against SARS-CoV-2 SDMs, followed by our opinion on the subject. 1) Issue: the virus is spreading and the population was not in equilibrium with climate or any other putative niche dimension in March, let alone today. Our thoughts: it was not in equilibrium and that is imperfect; however, SDMs have been useful for a number of non-equilibrium systems, like species invasions during their spreading phase (Václavík and Meentemeyer 2009), and waiting for equilibrium will mean predictions are no longer as useful to conduct (i.e., would only be helpful for a next outbreak of this virus). 2) Issue: the virus may have been spreading heavily or underreported in the Global South as of March. Our thoughts: surely this was partially true, but this may not completely explain observable climatic correlations. Even if we are working with 
385 incomplete data, it is hard to know if adding those data will significantly change conclusions

386

387

388

389

390

391

392

393

394

395

396

397

398

399

400

401

402

403

404

405

406

407

408

409

410

411

412

413

414

415

416

417

418 based on preliminary models (i.e., will the SARS-CoV-2 model still be indistinguishable from a human population model). Still, to mitigate this problem we focused on the more consistent USlevel data. 3) Issue: papers applying SDMs must strive for best practices to avoid common errors. Our thoughts: yes, we agree that best practices are indeed worth pursuing, even if not everyone agrees on what best practices may be. We have done our best to achieve the somewhat aspirational standards that have been put forth (Araújo et al. 2019a). We explicitly document this and summarize shortcomings that are inherent with a newly spreading system (Table 1). 4) Issue: caution should be taken in claims and dissemination of research that could impact public health policy. Our thoughts: yes, caution is advisable in terms of studies on dire subjects like SARS-CoV-2; however, cross pollination between disciplines has been important for many breakthroughs and advances in science.

Further caution towards distribution modeling methodology for SARS-CoV-2 in recent review literature highlights the likely limited effect climate has on a pathogen spread via direct transmission, and thus concludes that this tool is inappropriate in this situation (Carlson et al. 2020a, [b] 2020). Important confounding variables such as human interactions, public policy, and microclimate may mask any effects climate plays on this virus (Carlson et al. 2020b; Chipperfield et al. 2020). Due to this, epidemiological studies are more suited to understand patterns of transmission (Carlson et al. 2020b; Chipperfield et al. 2020; Carlson et al. 2020a). Importantly, given these problems with SDMs of SARS-CoV-2, there is concern that these studies may negatively affect public policy (Chipperfield et al. 2020; Carlson et al. 2020a, [b] 2020). Others continue to highlight the possible connections between climate and SARS-CoV-2 and advocate for continued research in this area (Araújo, Mestre, and Naimi 2020).

\section{Caveats and unknowns}

There are individuals who regularly go undetected for SARS-CoV-2 (e.g., those who lack symptoms or have mild symptoms) - currently estimated at up to $25 \%$ (Mandavilli 2020). This is of course an issue for all studies of SARS-CoV-2, but was likely especially true for March when testing was less widely available in the U.S. Obviously it is not ideal for modeling and forecasting; however, it is inherent in any study. In fact, we have far more data available for SARS-CoV-2 than we will ever have for the vast majority of viruses and biodiversity generally. Our results are based on data for a single, large country. While conducting an analysis on global data would have been ideal, we avoided this because this type of global analysis is known to have certain issues and inconsistencies (Chipperfield et al. 2020). While it may 
419

420

421

422

423

424

425

426

427

428

429

430

431

432

433

434

435

436

437

438

439

440

441

442

443

444

445

446

447

448

449

450

451

452

somewhat hobble our ability to forecast viral distributions at other time points, as there are surely non-analogous weather systems to come (i.e., no place in the U.S. in March was as hot as Death Valley, California is during full summer heat), we feel it was a worthy trade-off. Policy, social factors, and a variety of other variables were not included in this study, despite their obvious, known, or potential importance (Maier and Brockmann 2020; Leung et al. 2020; A. Miller et al. 2020); other variables such as wearing masks are also surely important for global patterns (Maier and Brockmann 2020; Leung et al. 2020). Unfortunately, data on these variables are often lacking in public databases. Our goals were to focus on a rather macro scale, which may be harder to do with policy data that can vary substantially from county to county, state to state, and, for a global study, country to country. While policies in the U.S. probably had not been implemented for long enough to tell their impact in March data, these changes (e.g., selfisolation and mask wearing) clearly and strongly influenced the trajectory of the virus after March.

\section{Data accessibility and mobilization}

We believe the New York Times (The New York Times 2020) providing robust countylevel data in an accessible repository with an open license for the U.S. sets an excellent standard that should be repeated by governments, academics, and other media organizations for other parts of the world so that this type of study may be better repeated in any country or globally. In a similar vein, we have made our analytical and modeling pipeline (along with figures) available (https://github.com/rsh249/cv19 enm/releases/tag/v0.0.5). We believe it is imperative for all pipelines and scripts to be made available for any SARS-CoV-2 research to ensure that models can be improved upon and any errors can be more quickly uncovered and resolved.

\section{Future directions}

There are many avenues to pursue regarding SARS-CoV-2 modeling and predictions. We are excited to see researchers from a variety of fields extending their toolkits towards understanding this virus. We hope that ecological studies like this and others can play a role without overcomplicating the research efforts put forth by epidemiologists. Still, studies should familiarize themselves with current critiques of SDMs for SARS-CoV-2 modeling and be cautious of their inputs and conclusions.

With improving data, we feel that future studies should better be able to examine the system globally while considering human populations and public policy efforts at curbing the 
453 virus. We also believe that it will at some point, in the U.S. and elsewhere, be worth examining 454 death rates across different areas, as it would be helpful to know if climate or other abiotic

455 variables might impact this statistic. Coupling regularly updated data with automated online

456 resources would also be particularly helpful in learning how this virus may spread.

457

\section{Conclusions}

459 SDMs from SARS-CoV-2 population-scaled cases did not appear to be distinguishable 460 from human population density for an early point in the pandemic for the U.S. Future studies

461 looking at climate's impact on this virus should, wherever possible, take into account human 462 population density in any analyses.

463

464 Acknowledgements

465 We thank those who are treating the sick, providing essential services, preventing viral 466 spread, quarantining alone, and helping others during this time of need; we thank the New York 467 Times for making their data publically available; we thank the other researchers who have been 468 providing a lively debate on best practices and how to make predictions at a point in time when 469 our methods may matter most; and we thank Peter Galante and Rob DeSalle for reviewing a 470 draft of this manuscript. 
471

472

473

\section{Figures and Table}

A 2020-03-02
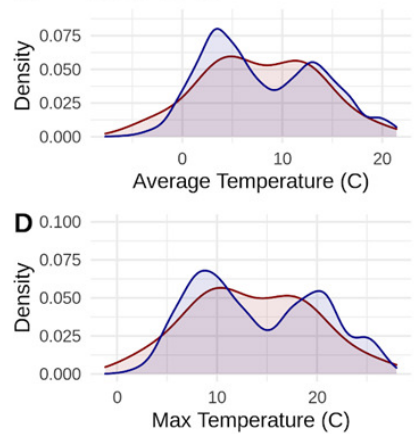

\section{$\circ$}
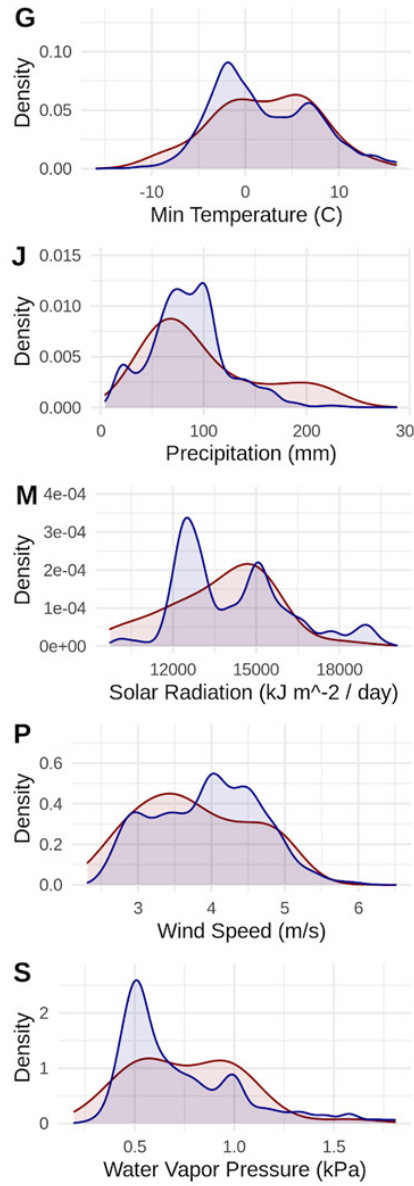

B 2020-03-16
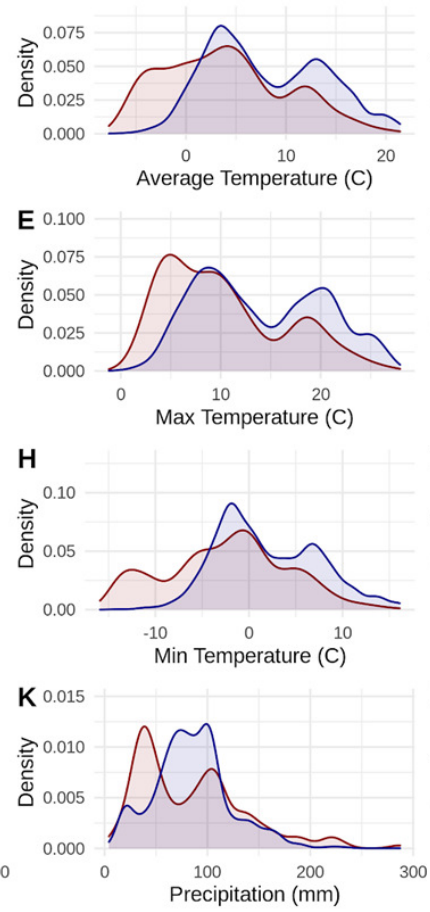

N $4 \mathrm{e}-04$

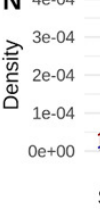
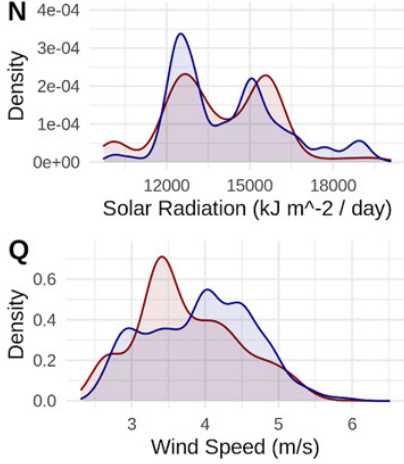

$\mathbf{T}$

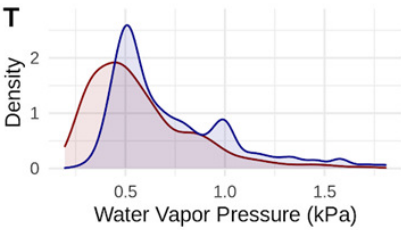

C $2020-03-30$
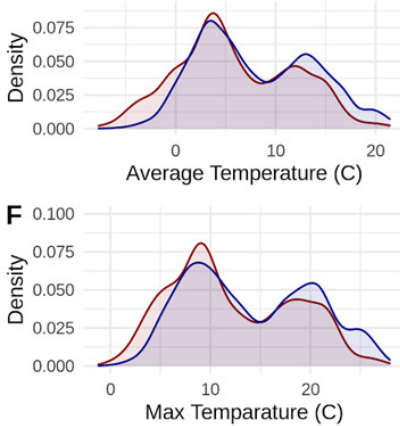

I
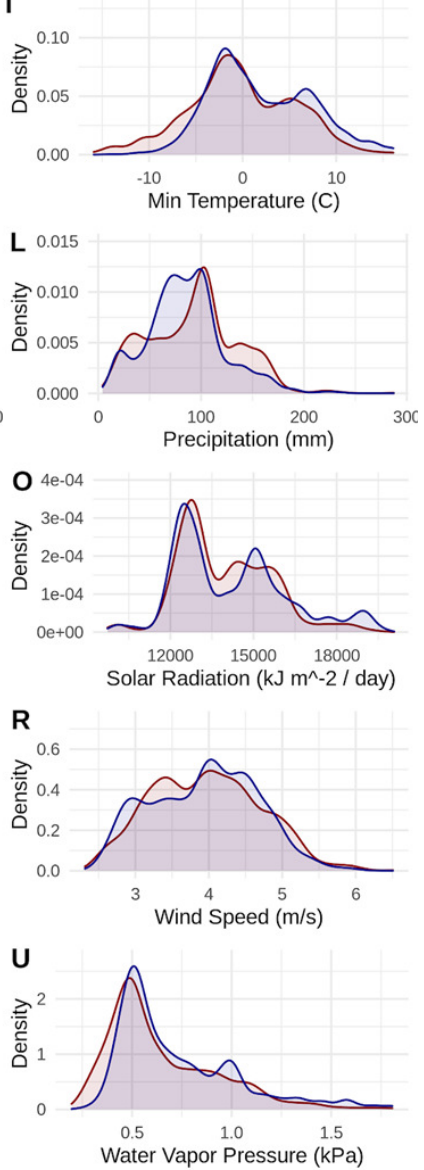

Figure 1. Probability densities of SARS-CoV-2 coronavirus cases (using population-scaled data; curves in red) compared to the probability densities of human populations (curves in blue) in each U.S. county for each of seven climate variables. Probability density curves are standardized to an area of one. 

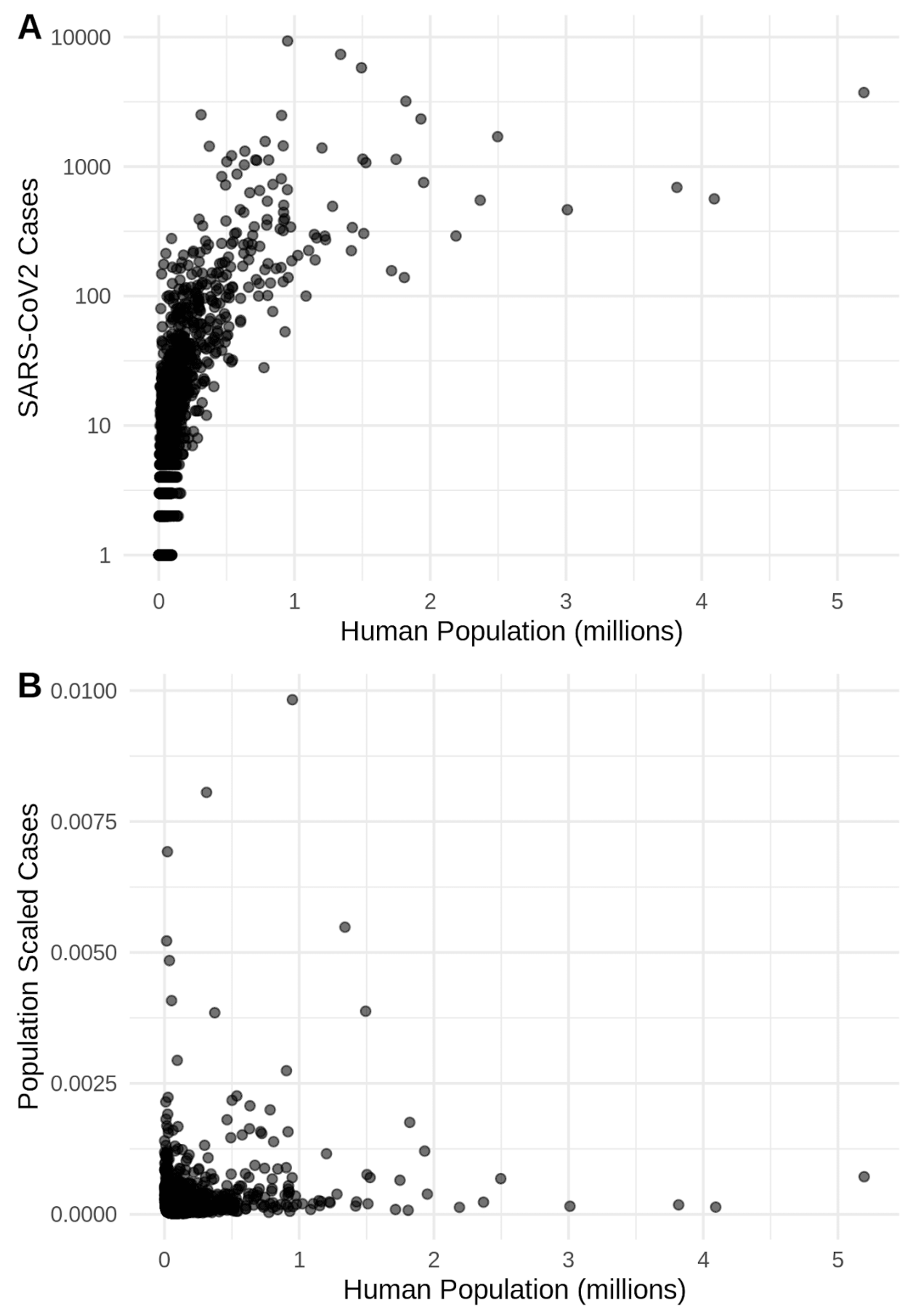

Figure 2. The relationship in the U.S. between human population size and SARS-CoV-2 coronavirus cases, using (A) total viral cases and (B) population-scaled viral cases. New York City, an outlying point, has been excluded for clearer visualization. 
A

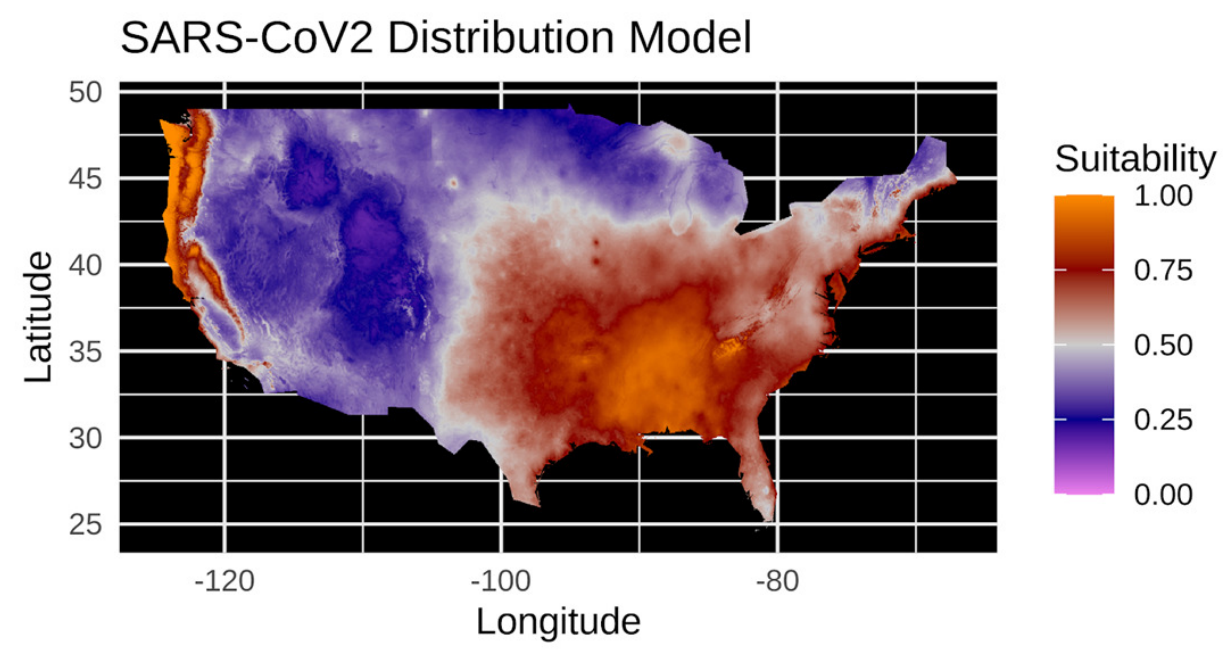

B

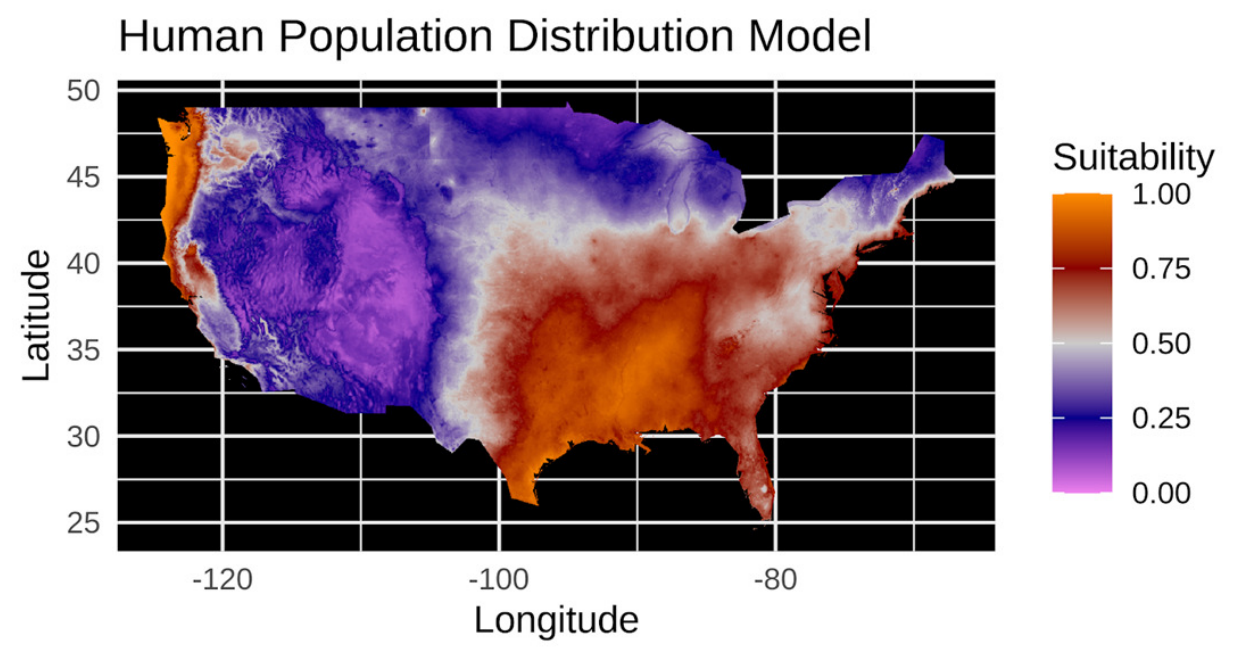

490

491

492

493

494

495

496

Figure 3. (A) Species distribution model of the SARS-CoV-2 coronavirus (using populationscaled data) for March 30, 2020. (B) Human population distribution model for the U.S. from 2010. 


\section{Overlap}

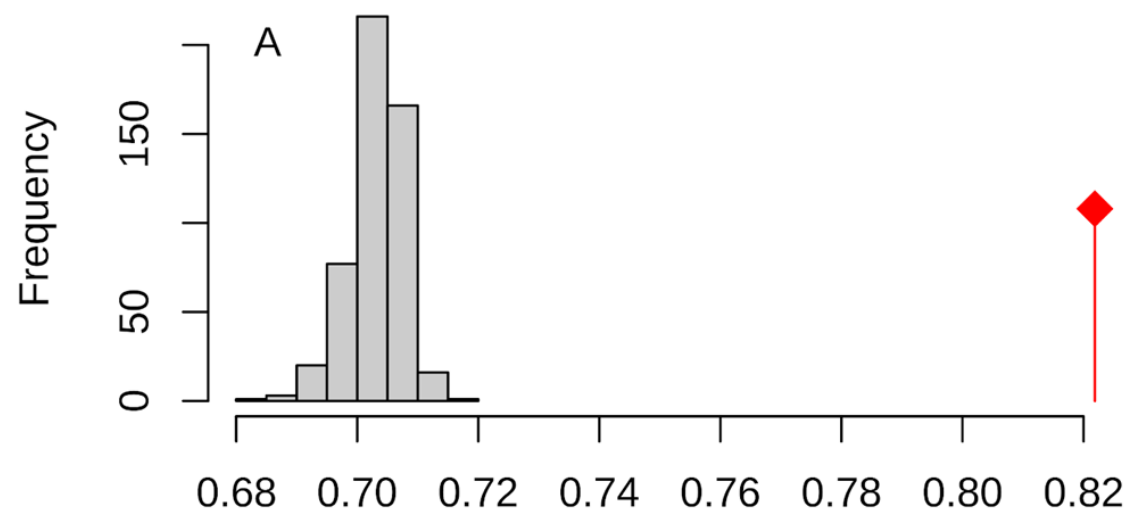

D

p.value $=0.002$

Similarity

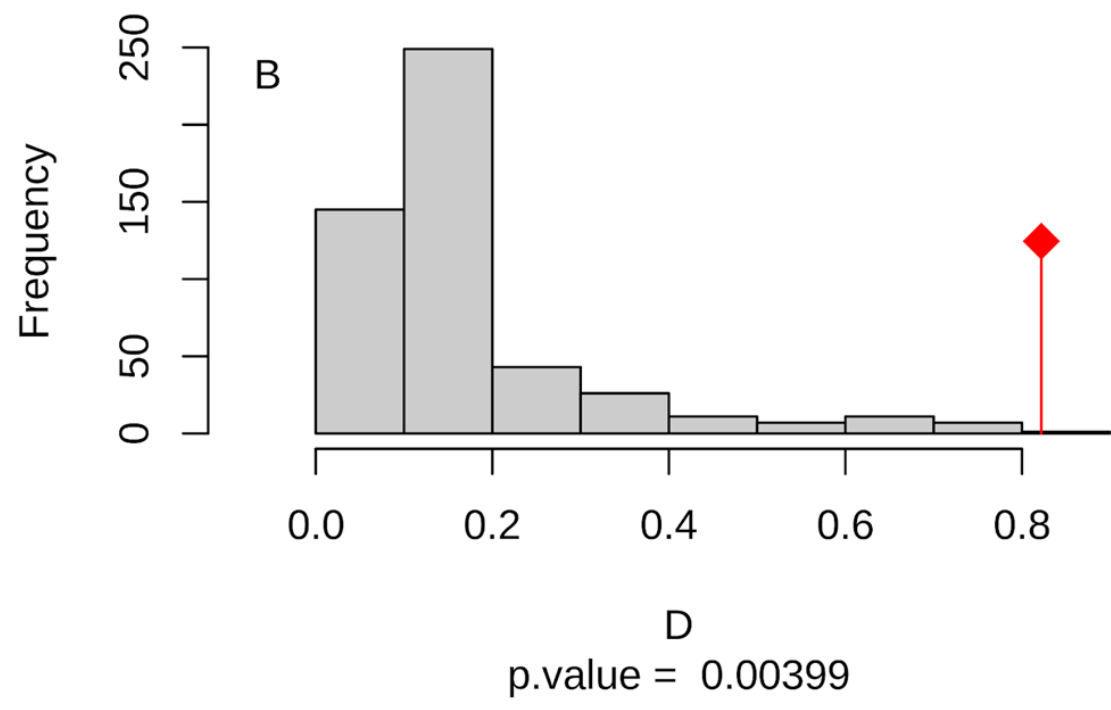

Figure 4. (A) Niche overlap and (B) similarity tests for Maxent species distribution models built 500 with population-scaled SARS-CoV-2 coronavirus data compared to one built with human

501 population density as occurrence data; actual model overlap indicated by a red marker in both plots. Significant $p$-values correspond to greater niche overlap or similarity than expected by random models.

505

506 
Table 1. Evaluation of our species distribution modeling practices against the best practices that have been proposed for this field (Araújo et al. 2019a).

\begin{tabular}{|c|c|c|}
\hline Guideline & Standard & Justification \\
\hline \multirow[t]{5}{*}{$\begin{array}{l}\text { Response } \\
\text { variables }\end{array}$} & A) Sampling: bronze & $\begin{array}{l}\text { Best data available; municipalities, local } \\
\text { governments, and states choose who to test. } \\
\text { Positive tests only reported. }\end{array}$ \\
\hline & B) Identification: gold & Assuming best practices in testing and reporting. \\
\hline & $\begin{array}{l}\text { C) Spatial accuracy: } \\
\text { bronze }\end{array}$ & $\begin{array}{l}\text { County assignments provide a rough georeference } \\
\text { for each record, but do not precisely describe where } \\
\text { transmission of the virus occurred. Spatial accuracy } \\
\text { unknown. Occurrences limited to identifiable county } \\
\text { level localities. }\end{array}$ \\
\hline & $\begin{array}{l}\text { D) Environmental } \\
\text { extent: deficient }\end{array}$ & $\begin{array}{l}\text { Limiting the study area to the continental U.S. is } \\
\text { unlikely to adequately test environmental } \\
\text { boundaries. }\end{array}$ \\
\hline & $\begin{array}{l}\text { E) Geographic extent: } \\
\text { bronze }\end{array}$ & Study area to include current range in the U.S. \\
\hline \multirow[t]{3}{*}{$\begin{array}{l}\text { Predictor } \\
\text { variables }\end{array}$} & $\begin{array}{l}\text { A) Selection of } \\
\text { candidates: } \\
\text { bronze/deficient }\end{array}$ & $\begin{array}{l}\text { Unclear and not well documented correlations } \\
\text { between SARS-CoV-2 transmission and climate. At } \\
\text { best, distal variables with weak, indirect control on } \\
\text { the distribution. }\end{array}$ \\
\hline & $\begin{array}{l}\text { B) Spatial and temporal } \\
\text { resolution: deficient }\end{array}$ & $\begin{array}{l}\text { Variables sampled from a } 2.5 \text { arcminute grid for all } \\
\text { cells within } 5 \mathrm{~km} \text { of each occurrence point. Mean } \\
\text { value used for modeling. Monthly climate averages } \\
\text { as predictors for end of March occurrence data. }\end{array}$ \\
\hline & C) Uncertainty: bronze & $\begin{array}{l}\text { Temporal and spatial uncertainty in occurrence data } \\
\text { has unquantified potential effects on the model } \\
\text { output. }\end{array}$ \\
\hline \multirow[t]{3}{*}{$\begin{array}{l}\text { Model } \\
\text { building }\end{array}$} & $\begin{array}{l}\text { A) Model Complexity: } \\
\text { silver }\end{array}$ & $\begin{array}{l}\text { ENMeval for model testing and selection (maximize } \\
\text { testing AUC and minimize AICc in the case of ties) } \\
\text { using internal cross validation through the block } \\
\text { resampling method. }\end{array}$ \\
\hline & $\begin{array}{l}\text { B) Treatment of } \\
\text { response bias: silver }\end{array}$ & $\begin{array}{l}\text { Internal cross validation to evaluate bias effects in } \\
\text { different models. }\end{array}$ \\
\hline & $\begin{array}{l}\text { C) Treatment of } \\
\text { collinearity: bronze }\end{array}$ & $\begin{array}{l}\text { "Approximate methods are applied" - Predictor } \\
\text { variables hand selected from monthly climate data } \\
\text { available to avoid collinearity (i.e., used only Tmax } \\
\text { and not Tavg or Tmin). }\end{array}$ \\
\hline
\end{tabular}




\begin{tabular}{|l|l|l|}
\hline & D) Uncertainty: bronze & $\begin{array}{l}\text { Multiple Maxent model parameters tested, but only } \\
\text { the optimal model presented. }\end{array}$ \\
\hline $\begin{array}{l}\text { Model } \\
\text { evaluation }\end{array}$ & $\begin{array}{l}\text { A) Evaluation of model } \\
\text { assumptions: gold/silver }\end{array}$ & $\begin{array}{l}\text { Select robust models from all tested models with } \\
\text { ENMeval. }\end{array}$ \\
\hline & $\begin{array}{l}\text { B) Evaluation of model } \\
\text { outputs: silver }\end{array}$ & $\begin{array}{l}\text { Evaluated against multiple, non-independent, } \\
\text { geographically structured sub-samples. }\end{array}$ \\
\hline & $\begin{array}{l}\text { C) Measures of model } \\
\text { performance: silver }\end{array}$ & $\begin{array}{l}\text { Suite of model performance metrics performed via } \\
\text { ENMeval. }\end{array}$ \\
\hline SUMMARY & $\begin{array}{l}\text { Mode of the scores: } \\
\text { bronze }\end{array}$ & $\begin{array}{l}\text { Model building and testing is generally robust, } \\
\text { but data and geographic scope are incomplete at } \\
\text { this time. }\end{array}$ \\
\hline
\end{tabular}



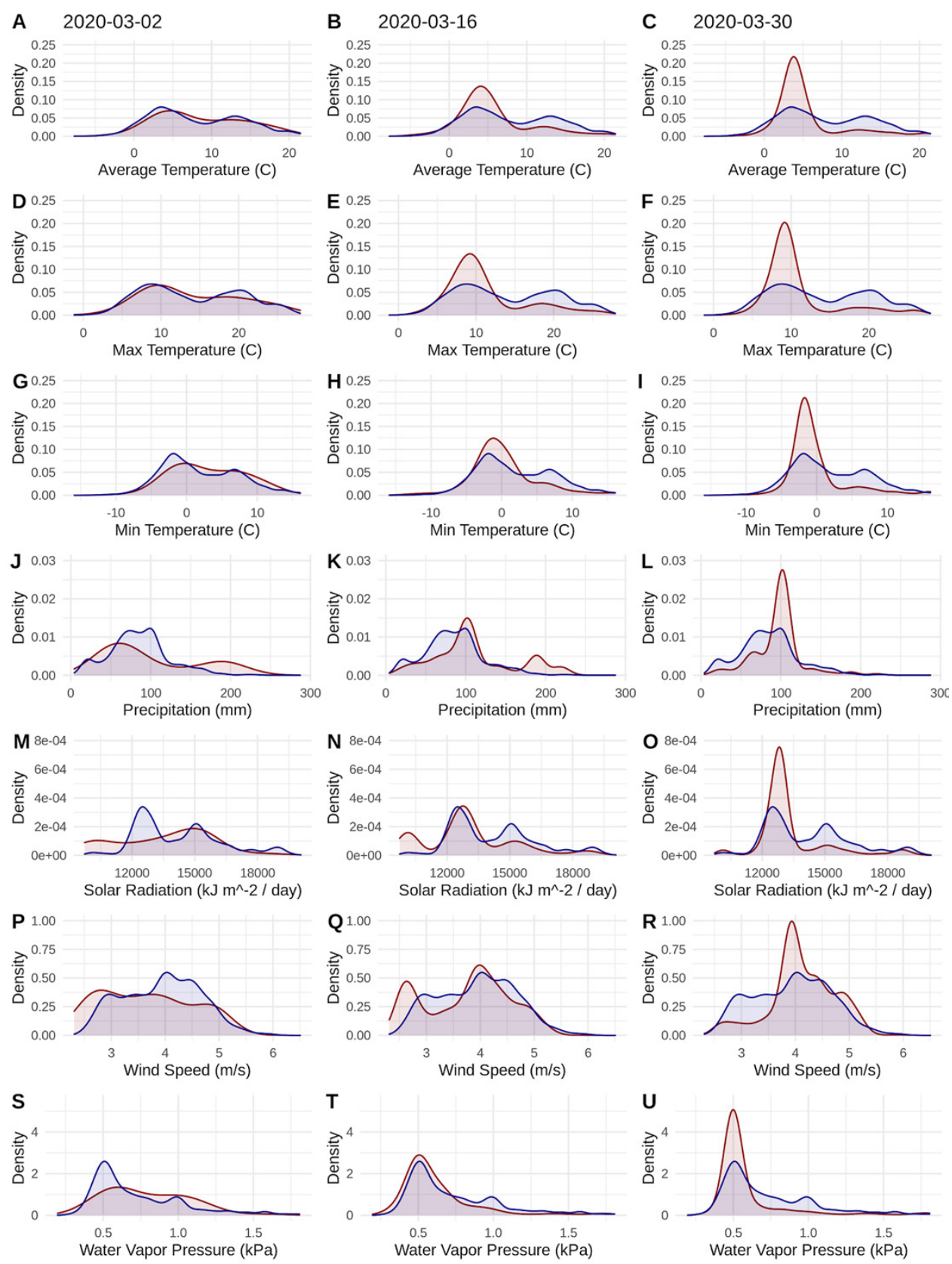

Figure S1. Equivalent of Figure 1, but using raw virus data. Probability densities of SARS-CoV-

5152 coronavirus cases (using raw data; curves in red) compared to the probability densities of

516 human populations (curves in blue) in each U.S. county for each of seven climate variables.

517 Probability density curves are standardized to an area of one. 
A

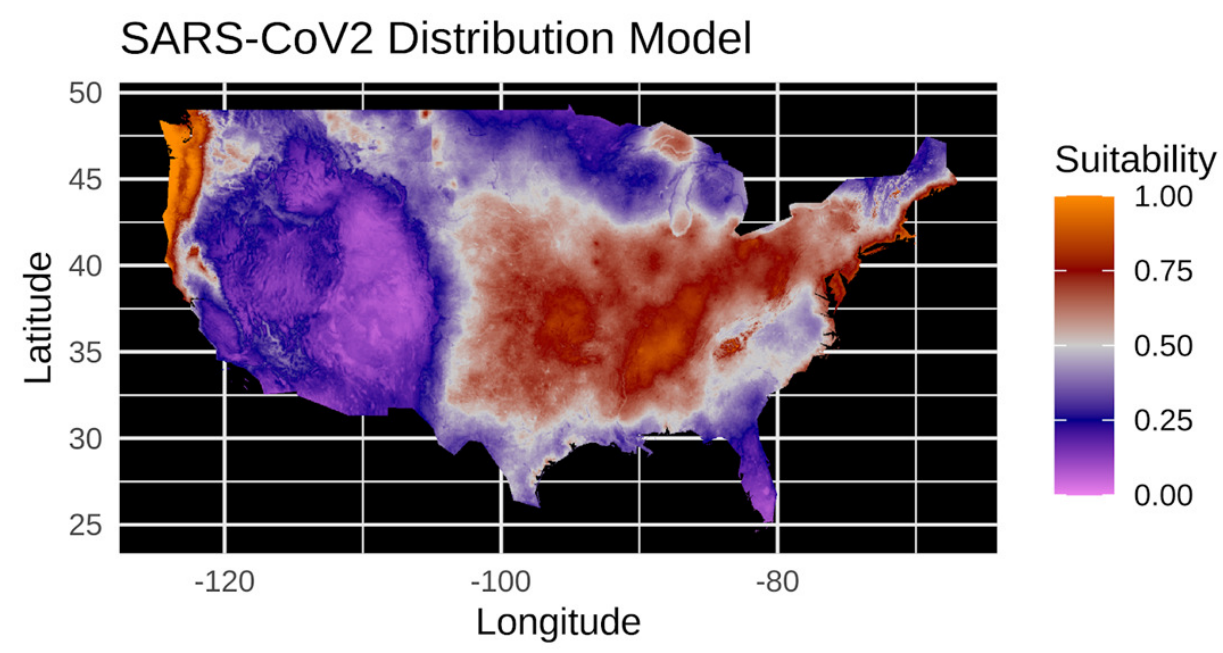

B

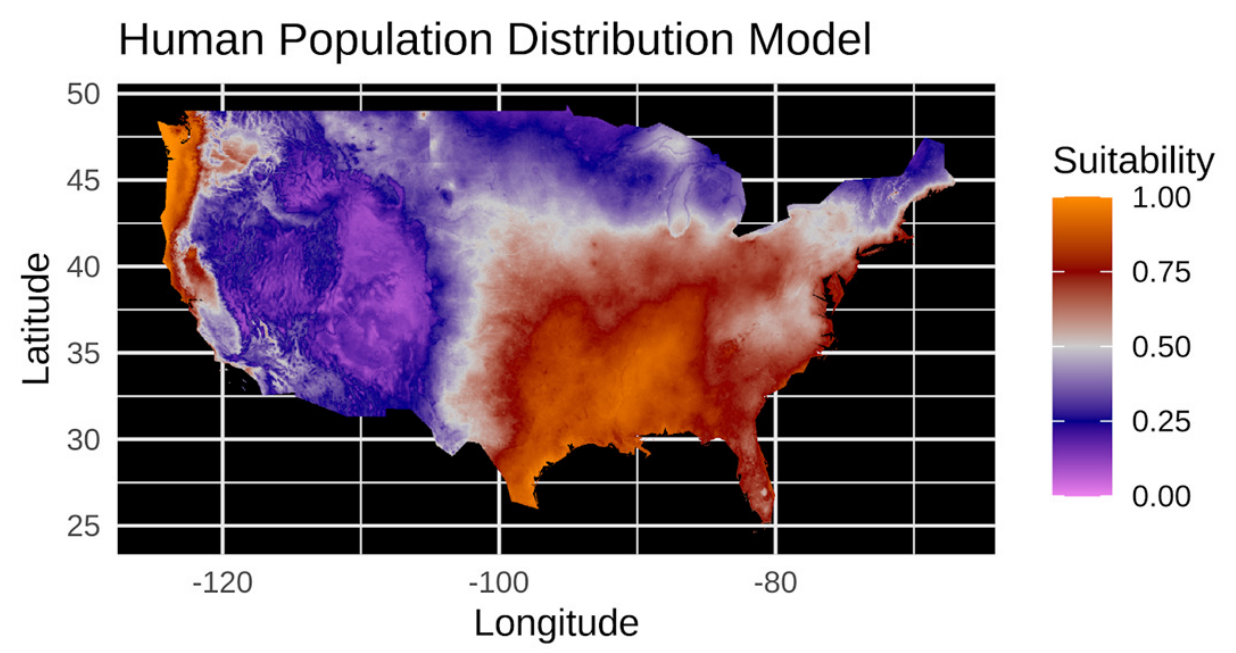

Figure S2. Equivalent of Figure 3, but using raw virus data. (A) Species distribution model of the SARS-CoV-2 coronavirus (using raw data) for March 30, 2020. (B) Human population 


\section{Overlap}

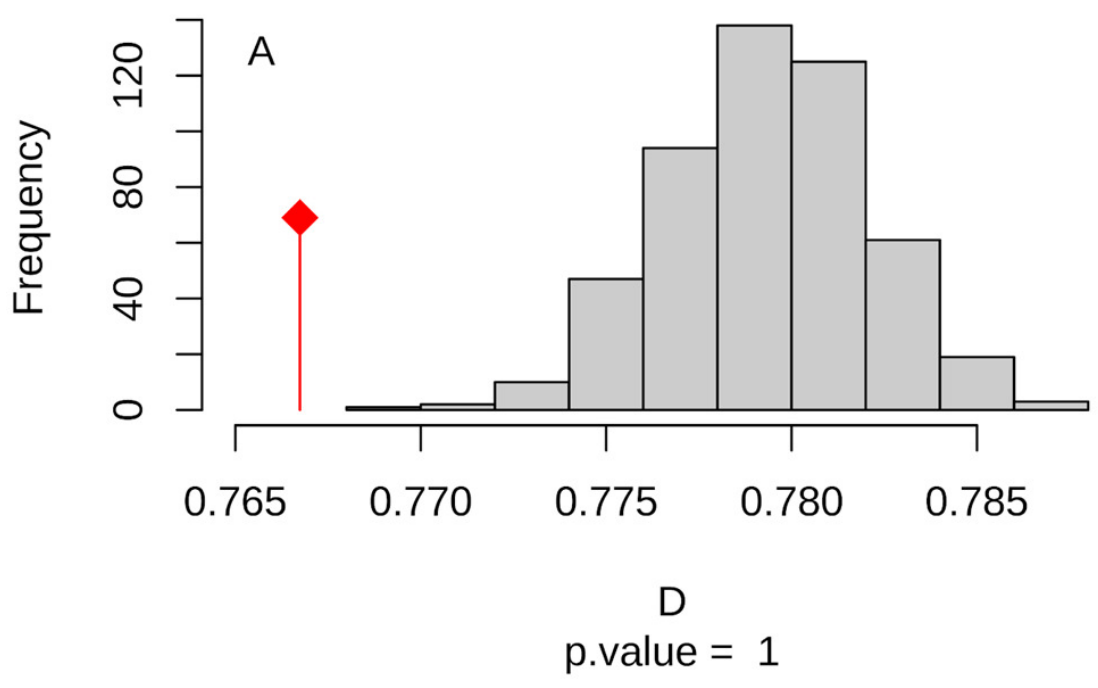

\section{Similarity}

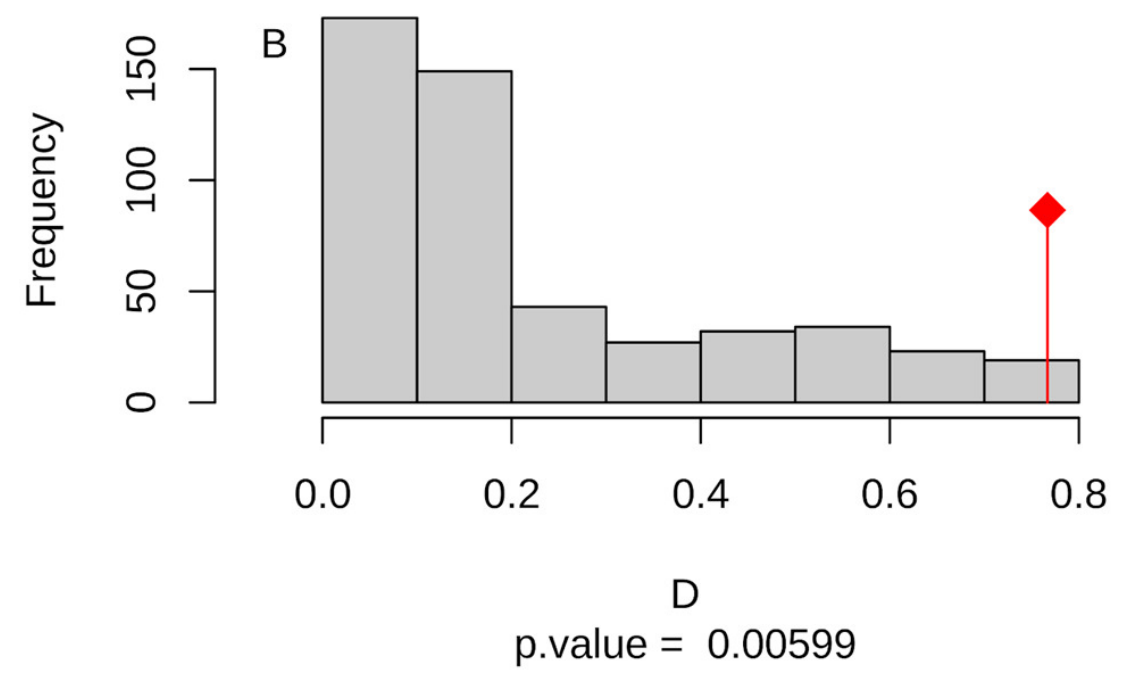

Figure S3. Equivalent of Figure 4, but using raw virus data. (A) Niche Overlap and (B) similarity tests for Maxent species distribution models built with SARS-CoV-2 coronavirus case data compared to one built with human population density as occurrence data; actual model overlap indicated by a red marker in both plots. Significant $p$-values correspond to greater niche overlap or similarity than expected by random models. 
535

536

537

538

539

540

541

542

543

544

545

546

547

548

549

550

551

552

553

554

555

556

557

558

559

560

561

562

563

564

565

566

567

568

569

570

571

572

573

574

575

576

577

578

579

580

581

582

583

584

\section{References}

Ahmadi, Mohsen, Abbas Sharifi, Shadi Dorosti, Saeid Jafarzadeh Ghoushchi, and Negar Ghanbari. 2020. "Investigation of Effective Climatology Parameters on COVID-19 Outbreak in Iran." The Science of the Total Environment 729 (August): 138705.

Almeida, Marco A. B. de, Edmilson Dos Santos, Jáder da C. Cardoso, Lucas G. da Silva, Rafael M. Rabelo, and Júlio César Bicca-Marques. 2019. "Predicting Yellow Fever Through Species Distribution Modeling of Virus, Vector, and Monkeys." EcoHealth 16 (1): 95-108.

Alvarez-Ramirez, Jose, and Monica Meraz. 2020. "Role of Meteorological Temperature and Relative Humidity in the January-February 2020 Propagation of 2019-nCoV in Wuhan, China." medRxiv, March, 2020.03.19.20039164.

Araújo, Miguel B., Robert P. Anderson, A. Márcia Barbosa, Colin M. Beale, Carsten F. Dormann, Regan Early, Raquel A. Garcia, et al. 2019a. "Standards for Distribution Models in Biodiversity Assessments." Science Advances 5 (1): eaat4858.

. 2019b. "Standards for Distribution Models in Biodiversity Assessments." Science Advances 5 (1): eaat 4858.

Araújo, Miguel B., Frederico Mestre, and Babak Naimi. 2020. "Ecological and Epidemiological Models Are Both Useful for SARS-CoV-2." Nature Ecology \& Evolution, June. https://doi.org/10.1038/s41559-020-1246-y.

Araújo, Miguel B., and Babak Naimi. 2020. "Spread of SARS-CoV-2 Coronavirus Likely to Be Constrained by Climate." Epidemiology. medRxiv.

Baker, Rachel E., Wenchang Yang, Gabriel A. Vecchi, C. Jessica E. Metcalf, and Bryan T. Grenfell. 2020. "Susceptible Supply Limits the Role of Climate in the Early SARS-CoV-2 Pandemic." Science. https://doi.org/10.1126/science.abc2535.

Bannister-Tyrrell, Melanie, Anne Meyer, Celine Faverjon, and Angus Cameron. 2020. "Preliminary Evidence That Higher Temperatures Are Associated with Lower Incidence of COVID-19, for Cases Reported Globally up to February 29 2020." medRxiv, March, 2020.03.18.20036731.

Barbet-Massin, Morgane, Quentin Rome, Claire Villemant, and Franck Courchamp. 2018. "Can Species Distribution Models Really Predict the Expansion of Invasive Species?" PloS One 13 (3): e0193085.

Bariotakis, Michail, George Sourvinos, Elias Castanas, and Stergios A. Pirintsos. 2020. "Climatic Influences on the Worldwide Spread of SARS-CoV-2." Www.medrxiv.org/. Cold Spring Harbor Laboratory. https://doi.org/10.1101/2020.03.19.20038158.

Bedford, Trevor, Steven Riley, lan G. Barr, Shobha Broor, Mandeep Chadha, Nancy J. Cox, Rodney S. Daniels, et al. 2015. "Global Circulation Patterns of Seasonal Influenza Viruses Vary with Antigenic Drift." Nature 523 (7559): 217-20.

Belkhiria, Jaber, Moh A. Alkhamis, and Beatriz Martínez-López. 2016. "Application of Species Distribution Modeling for Avian Influenza Surveillance in the United States Considering the North America Migratory Flyways." Scientific Reports 6 (September): 33161.

Bhatt, Samir, Peter W. Gething, Oliver J. Brady, Jane P. Messina, Andrew W. Farlow, Catherine L. Moyes, John M. Drake, et al. 2013. "The Global Distribution and Burden of Dengue." Nature 496 (7446): 504-7.

Broennimann, Olivier, Matthew C. Fitzpatrick, Peter B. Pearman, Blaise Petitpierre, Loïc Pellissier, Nigel G. Yoccoz, Wilfried Thuiller, et al. 2012. "Measuring Ecological Niche Overlap from Occurrence and Spatial Environmental Data." Global Ecology and Biogeography 21 (4): 481-97.

Bukhari, Qasim, and Yusuf Jameel. 2020. "Will Coronavirus Pandemic Diminish by Summer?" SSRN Electronic Journal. https://doi.org/10.2139/ssrn.3556998.

Carlson, Colin J., Joseph D. Chipperfield, Blas M. Benito, Richard J. Telford, and Robert B. O'Hara. 2020a. "Don't Gamble the COVID-19 Response on Ecological Hypotheses." Nature 
585

586

587

588

589

590

591

592

593

594

595

596

597

598

599

600

601

602

603

604

605

606

607

608

609

610

611

612

613

614

615

616

617

618

619

620

621

622

623

624

625

626

627

628

629

630

631

632

633

634

635

Ecology \& Evolution. https://doi.org/10.1038/s41559-020-1279-2.

Carlson, Colin J., Joseph D. Chipperfield, Blas M. Benito, Richard J. Telford, and Robert B. O'Hara. 2020b. "Species Distribution Models Are Inappropriate for COVID-19." Nature Ecology \& Evolution 4 (6): 770-71.

Carlson, Colin J., Eric R. Dougherty, and Wayne Getz. 2016. "An Ecological Assessment of the Pandemic Threat of Zika Virus." PLoS Neglected Tropical Diseases 10 (8): e0004968.

CDC NCIRD. 2020. "Coronavirus Disease 2019 (COVID-19): Cases in the U.S." CDC NCIRD. https://www.cdc.gov/coronavirus/2019-ncov/cases-updates/cases-in-us.html.

Chen, Biqing, Hao Liang, Xiaomin Yuan, Yingying Hu, Miao Xu, Yating Zhao, Binfen Zhang, Fang Tian, and Xuejun Zhu. 2020. "Roles of Meteorological Conditions in COVID-19 Transmission on a Worldwide Scale." medRxiv, March, 2020.03.16.20037168.

Chinazzi, Matteo, Jessica T. Davis, Marco Ajelli, Corrado Gioannini, Maria Litvinova, Stefano Merler, Ana Pastore Y Piontti, et al. 2020. "The Effect of Travel Restrictions on the Spread of the 2019 Novel Coronavirus (COVID-19) Outbreak." Science, March.

https://doi.org/10.1126/science.aba9757.

Chipperfield, Joseph Daniel, Blas M. Benito, Robert O'Hara, Richard James Telford, and Colin J. Carlson. 2020. "On the Inadequacy of Species Distribution Models for Modelling the Spread of SARS-CoV-2: Response to Araújo and Naimi." EcoEvoRxiv.

Di Cola, Valeria, Valeria Di Cola, Olivier Broennimann, Blaise Petitpierre, Frank T. Breiner, Manuela D'Amen, Christophe Randin, et al. 2017. "Ecospat: An R Package to Support Spatial Analyses and Modeling of Species Niches and Distributions." Ecography 40 (6): 774-87.

Dong, Ensheng, Hongru Du, and Lauren Gardner. 2020. "An Interactive Web-Based Dashboard to Track COVID-19 in Real Time." The Lancet Infectious Diseases, February. https://doi.org/10.1016/S1473-3099(20)30120-1.

Elith, Jane, and John R. Leathwick. 2009. "Species Distribution Models: Ecological Explanation and Prediction across Space and Time." Annual Review of Ecology, Evolution, and Systematics 40 (1): 677-97.

Elith, Jane, Steven J. Phillips, Trevor Hastie, Miroslav Dudík, Yung En Chee, and Colin J. Yates. 2011. "A Statistical Explanation of MaxEnt for Ecologists." Diversity and Distributions 17 (1): 43-57.

Fang, Li-Qun, Xin-Lou Li, Kun Liu, Yin-Jun Li, Hong-Wu Yao, Song Liang, Yang Yang, Zi-Jian Feng, Gregory C. Gray, and Wu-Chun Cao. 2013. "Mapping Spread and Risk of Avian Influenza A (H7N9) in China." Scientific Reports 3 (September): 2722.

Ficetola, Gentile Francesco, and Diego Rubolini. 2020. "Climate Affects Global Patterns of COVID-19 Early Outbreak Dynamics." medRxiv, March, 2020.03.23.20040501.

Fick, Stephen E., and Robert J. Hijmans. 2017. "WorldClim 2: New 1-Km Spatial Resolution Climate Surfaces for Global Land Areas." International Journal of Climatology 37 (12): 4302-15.

Fisman, D. 2012. "Seasonality of Viral Infections: Mechanisms and Unknowns." Clinical Microbiology and Infection: The Official Publication of the European Society of Clinical Microbiology and Infectious Diseases 18 (10): 946-54.

Fois, Mauro, Alba Cuena-Lombraña, Giuseppe Fenu, and Gianluigi Bacchetta. 2018. "Using Species Distribution Models at Local Scale to Guide the Search of Poorly Known Species: Review, Methodological Issues and Future Directions." Ecological Modelling 385: 124-32.

Galante, Peter J., Babatunde Alade, Robert Muscarella, Sharon A. Jansa, Steven M. Goodman, and Robert P. Anderson. 2018. "The Challenge of Modeling Niches and Distributions for Data-Poor Species: A Comprehensive Approach to Model Complexity." Ecography 41 (5): 726-36.

Gaunt, E. R., A. Hardie, E. C. J. Claas, P. Simmonds, and K. E. Templeton. 2010. "Epidemiology and Clinical Presentations of the Four Human Coronaviruses 229E, HKU1, 
636

637

638

639

640

641

642

643

644

645

646

647

648

649

650

651

652

653

654

655

656

657

658

659

660

661

662

663

664

665

666

667

668

669

670

671

672

673

674

675

676

677

678

679

680

681

682

683

684

685

686

NL63, and OC43 Detected over 3 Years Using a Novel Multiplex Real-Time PCR Method." Journal of Clinical Microbiology 48 (8): 2940-47.

Guisan, Antoine, and Wilfried Thuiller. 2005. "Predicting Species Distribution: Offering More than Simple Habitat Models." Ecology Letters 8 (9): 993-1009.

Hernandez, Pilar A., Catherine H. Graham, Lawrence L. Master, and Deborah L. Albert. 2006. "The Effect of Sample Size and Species Characteristics on Performance of Different Species Distribution Modeling Methods." Ecography 29 (5): 773-85.

Holshue, Michelle L., Chas DeBolt, Scott Lindquist, Kathy H. Lofy, John Wiesman, Hollianne Bruce, Christopher Spitters, et al. 2020. "First Case of 2019 Novel Coronavirus in the United States." The New England Journal of Medicine 382 (10): 929-36.

IHME COVID-19 team, and Christopher J. L. Murray. 2020. "Forecasting COVID-19 Impact on Hospital Bed-Days, ICU-Days, Ventilator-Days and Deaths by U.S. State in the next 4 Months." Infectious Diseases (except HIVIAIDS). medRxiv.

Johnson, Erica E., Luis E. Escobar, and Carlos Zambrana-Torrelio. 2019. "An Ecological Framework for Modeling the Geography of Disease Transmission." Trends in Ecology \& Evolution 34 (7): 655-68.

Katz, Tatum S., and Amanda J. Zellmer. 2018. "Comparison of Model Selection Technique Performance in Predicting the Spread of Newly Invasive Species: A Case Study with Batrachochytrium Salamandrivorans." Biological Invasions 20 (8): 2107-19.

KCDC. 2020. "The Updates on COVID-19 in Korea as of February 25." Seoul, Korea. 2020. Kiedrzyński, Marcin, Katarzyna M. Zielińska, Agnieszka Rewicz, and Edyta Kiedrzyńska. 2017. "Habitat and Spatial Thinning Improve the Maxent Models Performed with Incomplete Data." Journal of Geophysical Research: Biogeosciences 122 (6): 1359-70.

Kucharski, Adam J., Timothy W. Russell, Charlie Diamond, Yang Liu, John Edmunds, Sebastian Funk, Rosalind M. Eggo, et al. 2020. "Early Dynamics of Transmission and Control of COVID-19: A Mathematical Modelling Study." The Lancet Infectious Diseases, March. https://doi.org/10.1016/S1473-3099(20)30144-4.

Larson, Scott R., John P. DeGroote, Lyric C. Bartholomay, and Ramanathan Sugumaran. 2010. "Ecological Niche Modeling of Potential West Nile Virus Vector Mosquito Species in lowa." Journal of Insect Science 10: 110.

Leonhardt, David. 2020. "The Unique U.S. Failure to Control the Virus." The New York Times, August 6, 2020.

Leung, Nancy H. L., Daniel K. W. Chu, Eunice Y. C. Shiu, Kwok-Hung Chan, James J. McDevitt, Benien J. P. Hau, Hui-Ling Yen, et al. 2020. "Respiratory Virus Shedding in Exhaled Breath and Efficacy of Face Masks." Nature Medicine 21 (April): 274.

Lippi, Giuseppe, Ana-Maria Simundic, and Mario Plebani. 2020. "Potential Preanalytical and Analytical Vulnerabilities in the Laboratory Diagnosis of Coronavirus Disease 2019 (COVID19)." Clinical Chemistry and Laboratory Medicine, March. https://doi.org/10.1515/cclm2020-0285.

Lofgren, Eric, N. H. Fefferman, Y. N. Naumov, J. Gorski, and E. N. Naumova. 2007. "Influenza Seasonality: Underlying Causes and Modeling Theories." Journal of Virology 81 (11): 5429-36.

Machado-Machado, Elia Axinia. 2012. "Empirical Mapping of Suitability to Dengue Fever in Mexico Using Species Distribution Modeling." Applied Geography. https://doi.org/10.1016/j.apgeog.2011.06.011.

Maier, Benjamin F., and Dirk Brockmann. 2020. "Effective Containment Explains SubExponential Growth in Confirmed Cases of Recent COVID-19 Outbreak in Mainland China." arXiv. https://doi.org/10.1101/2020.02.18.20024414.

Mandavilli, Apoorva. 2020. "Infected but Feeling Fine: The Unwitting Coronavirus Spreaders." The New York Times, 2020.

Messina, Jane P., David M. Pigott, Nick Golding, Kirsten A. Duda, John S. Brownstein, Daniel J.

Peer] reviewing PDF | (2020:05:48694:2:0:NEW 17 Sep 2020) 
687

688

689

690

691

692

693

694

695

696

697

698

699

700

701

702

703

704

705

706

707

708

709

710

711

712

713

714

715

716

717

718

719

720

721

722

723

724

725

726

727

728

729

730

731

732

733

734

735

736

737

Weiss, Harry Gibson, et al. 2015. "The Global Distribution of Crimean-Congo Hemorrhagic Fever." Transactions of the Royal Society of Tropical Medicine and Hygiene 109 (8): 50313.

Miller, Aaron, Mac Josh Reandelar, Kimberly Fasciglione, Violeta Roumenova, Yan Li, and Gonzalo H. Otazu. 2020. "Correlation between Universal BCG Vaccination Policy and Reduced Morbidity and Mortality for COVID-19: An Epidemiological Study." Epidemiology. medRxiv.

Miller, Robin H., Penny Masuoka, Terry A. Klein, Heung-Chul Kim, Todd Somer, and John Grieco. 2012. "Ecological Niche Modeling to Estimate the Distribution of Japanese Encephalitis Virus in Asia." PLoS Neglected Tropical Diseases 6 (6): e1678.

Muscarella, Robert, Peter J. Galante, Mariano Soley-Guardia, Robert A. Boria, Jamie M. Kass, María Uriarte, and Robert P. Anderson. 2014. "ENMeval: An R Package for Conducting Spatially Independent Evaluations and Estimating Optimal Model Complexity forMaxentecological Niche Models." Methods in Ecology and Evolution. https://doi.org/10.1111/2041-210x.12261.

Notari, Alessio. 2020. "Temperature Dependence of COVID-19 Transmission." arXiv. https://doi.org/10.1101/2020.03.26.20044529.

Paez, Antonio, Fernando A. Lopez, Tatiane Menezes, Renata Cavalcanti, and Maira Galdino da Rocha Pitta. 2020. "A Spatio-Temporal Analysis of the Environmental Correlates of COVID-19 Incidence in Spain." Geographical Analysis. https://doi.org/10.1111/gean.12241.

Pearson, Richard G., Christopher J. Raxworthy, Miguel Nakamura, and A. Townsend Peterson. 2006. "Predicting Species Distributions from Small Numbers of Occurrence Records: A Test Case Using Cryptic Geckos in Madagascar." Journal of Biogeography 34 (1): 102-17.

Peterson, A. T. 2001. "Predicting Species' Geographic Distributions Based on Ecological Niche Modeling." The Condor 103 (3): 599.

Peterson, A. T., Jorge Soberón, Richard G. Pearson, Robert P. Anderson, Enrique MartínezMeyer, Miguel Nakamura, and Miguel B. Araújo. 2011. Ecological Niches and Geographic Distributions (MPB-49). Princeton University Press.

Phillips, Steven. 2017. Maxnet: Fitting "Maxent" Species Distribution Models with "Glmnet" (version 0.1.2). https://cran.r-project.org/web/packages/maxnet/index.html.

Pigott, David M., Samir Bhatt, Nick Golding, Kirsten A. Duda, Katherine E. Battle, Oliver J. Brady, Jane P. Messina, et al. 2014. "Global Distribution Maps of the Leishmaniases." eLife 3 (June). https://doi.org/10.7554/eLife.02851.

Pigott, David M., Nick Golding, Adrian Mylne, Zhi Huang, Andrew J. Henry, Daniel J. Weiss, Oliver J. Brady, et al. 2014. "Mapping the Zoonotic Niche of Ebola Virus Disease in Africa." eLife 3 (September): e04395.

Pigott, David M., Nick Golding, Adrian Mylne, Zhi Huang, Daniel J. Weiss, Oliver J. Brady, Moritz U. G. Kraemer, and Simon I. Hay. 2015. "Mapping the Zoonotic Niche of Marburg Virus Disease in Africa." Transactions of the Royal Society of Tropical Medicine and Hygiene 109 (6): 366-78.

Price, Rory Henry Macgregor, Catriona Graham, and Sandeep Ramalingam. 2019. "Association between Viral Seasonality and Meteorological Factors." Scientific Reports 9 (1): 929.

Qi, Hongchao, Shuang Xiao, Runye Shi, Michael P. Ward, Yue Chen, Wei Tu, Qing Su, Wenge Wang, Xinyi Wang, and Zhijie Zhang. 2020. "COVID-19 Transmission in Mainland China Is Associated with Temperature and Humidity: A Time-Series Analysis." The Science of the Total Environment 728 (August): 138778.

R Core Team. 2019. R: A Language and Environment for Statistical Computing (version 3.6.2). Vienna, Austria. https://www.R-project.org.

Richman, Rebecca, Diawo Diallo, Mawlouth Diallo, Amadou A. Sall, Oumar Faye, Cheikh T. Diagne, Ibrahima Dia, Scott C. Weaver, Kathryn A. Hanley, and Michaela Buenemann. 2018. "Ecological Niche Modeling of Aedes Mosquito Vectors of Chikungunya Virus in

Peer) reviewing PDF | (2020:05:48694:2:0:NEW 17 Sep 2020) 
738

739

740

741

742

743

744

745

746

747

748

749

750

751

752

753

754

755

756

757

758

759

760

761

762

763

764

765

766

767

768

769

770

771

772

773

774

775

776

777

Southeastern Senegal." Parasites \& Vectors 11 (1): 255.

Rosario, Denes K. A., Yhan S. Mutz, Patricia C. Bernardes, and Carlos A. Conte-Junior. 2020. "Relationship between COVID-19 and Weather: Case Study in a Tropical Country." International Journal of Hygiene and Environmental Health. https://doi.org/10.1016/j.ijheh.2020.113587.

Rothan, Hussin A., and Siddappa N. Byrareddy. 2020. "The Epidemiology and Pathogenesis of Coronavirus Disease (COVID-19) Outbreak.” Journal of Autoimmunity. https://doi.org/10.1016/j.jaut.2020.102433.

Sagripanti, Jose-luis, and C. David Lytle. 2020. "Estimated Inactivation of Coronaviruses by Solar Radiation With Special Reference to COVID-19." Photochemistry and Photobiology. https://doi.org/10.1111/php.13293.

Sajadi, Mohammad M., Parham Habibzadeh, Augustin Vintzileos, Shervin Shokouhi, Fernando Miralles-Wilhelm, and Anthony Amoroso. 2020. "Temperature and Latitude Analysis to Predict Potential Spread and Seasonality for COVID-19." SSRN Electronic Journal. https://doi.org/10.2139/ssrn.3550308.

The COVID Tracking Project. 2020. https://covidtracking.com.

The New York Times. 2020. "Data from The New York Times, Based on Reports from State and Local Health Agencies." https://github.com/nytimes/covid-19-data.

Václavík, Tomáš, and Ross K. Meentemeyer. 2009. "Invasive Species Distribution Modeling (iSDM): Are Absence Data and Dispersal Constraints Needed to Predict Actual Distributions?" Ecological Modelling 220 (23): 3248-58.

Walker, Kyle, Kris Eberwein, and Matt Herman. 2020. "Tidycensus: Load U.S. Census Boundary and Attribute Data as 'Tidyverse' and 'Sf'-Ready Data Frames. R Package Version 0.9.5." https://cran.r-project.org/web/packages/tidycensus/index.html.

Wang, Mao, Aili Jiang, Lijuan Gong, Lina Luo, Wenbin Guo, Chuyi Li, Jing Zheng, et al. 2020. "Temperature Significant Change COVID-19 Transmission in 429 Cities." medRxiv, February, 2020.02.22.20025791.

Warren, Dan L., Richard E. Glor, and Michael Turelli. 2008. "Environmental Niche Equivalency versus Conservatism: Quantitative Approaches to Niche Evolution." Evolution; International Journal of Organic Evolution 62 (11): 2868-83.

Wesolowski, Amy, Elisabeth Zu Erbach-Schoenberg, Andrew J. Tatem, Christopher Lourenço, Cecile Viboud, Vivek Charu, Nathan Eagle, et al. 2017. "Multinational Patterns of Seasonal Asymmetry in Human Movement Influence Infectious Disease Dynamics." Nature Communications 8 (1): 2069.

Wickham, Hadley. 2009. ggplot2: Elegant Graphics for Data Analysis. Springer Science \& Business Media.

Wu, Yu, Wenzhan Jing, Jue Liu, Qiuyue Ma, Jie Yuan, Yaping Wang, Min Du, and Min Liu. 2020. "Effects of Temperature and Humidity on the Daily New Cases and New Deaths of COVID-19 in 166 Countries." The Science of the Total Environment 729 (August): 139051.

Peer] reviewing PDF | (2020:05:48694:2:0:NEW 17 Sep 2020) 


\section{Figure 1}

Figure 1. Probability densities of SARS-CoV-2 coronavirus cases

Figure 1. Probability densities of SARS-CoV-2 coronavirus cases (using population scaled data; curves in red) compared to the probability densities of human populations (curves in blue) in each US county for each of seven climate variables. Probability density curves are standardized to an area of one. 
A $2020-03-02$
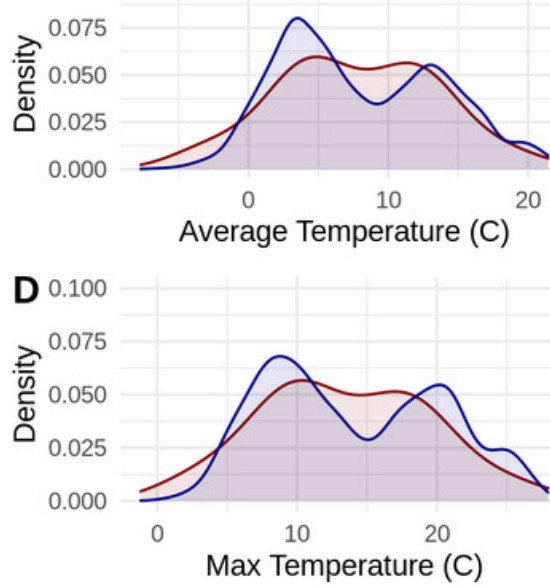

G

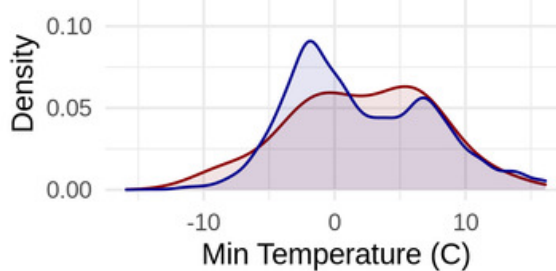

J 0.015

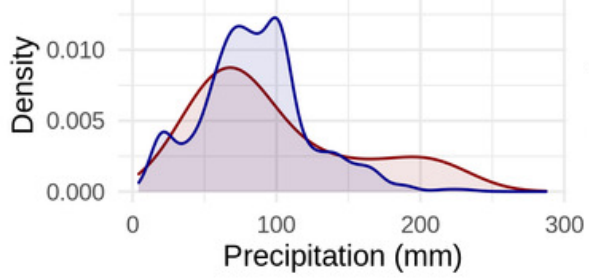

M 4e-04

$\overbrace{\frac{5}{\complement}}^{3 e-04}$ 1e-04 $0 \mathrm{e}+00$

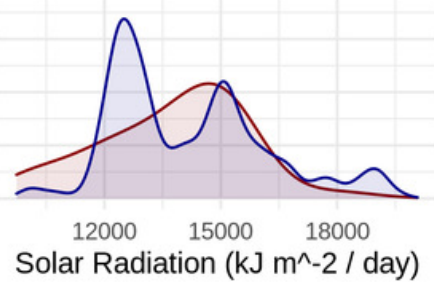

P

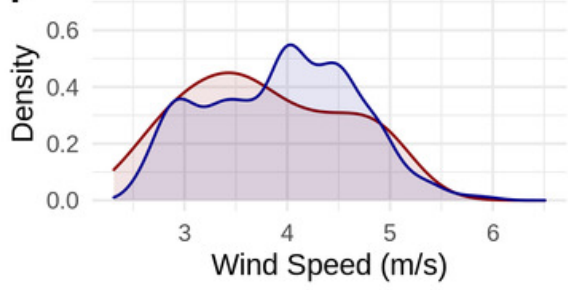

$\mathbf{S}$

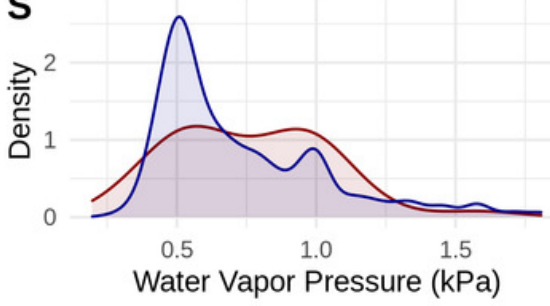

B $2020-03-16$

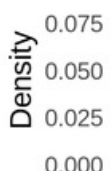

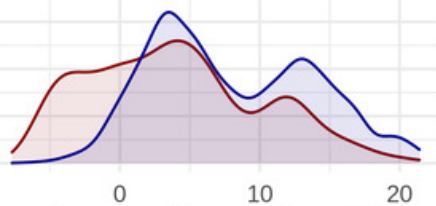

Average Temperature (C)

E 0.100

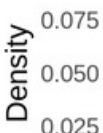

0.000

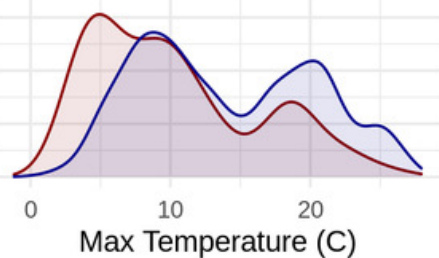

H

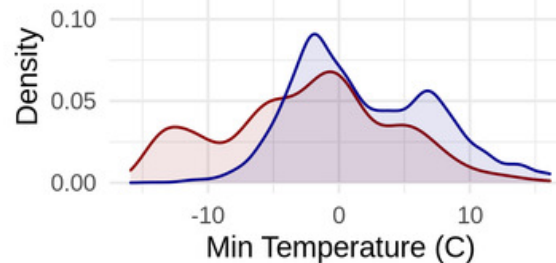

K 0.015

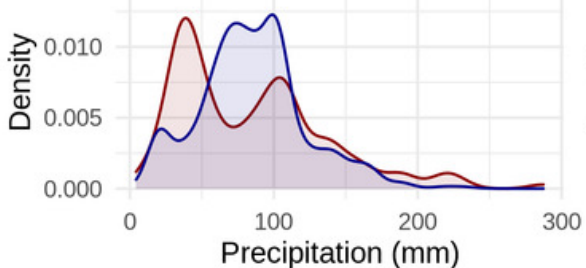

N $4 \mathrm{e}-04$

$\overbrace{\bar{\omega}}^{\complement}$
$2 \mathrm{e}-04$
$0 \mathrm{e}-04$
$0 \mathrm{e}+00$

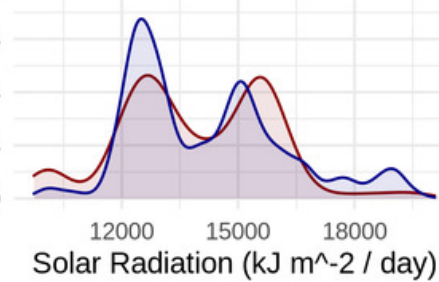

Q

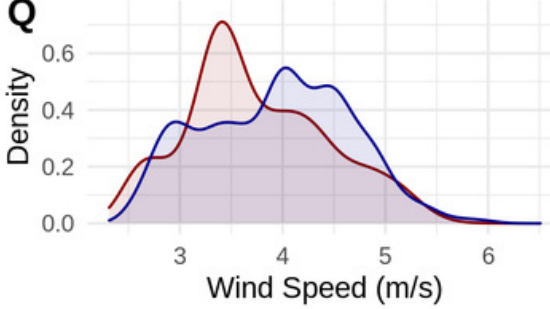

T

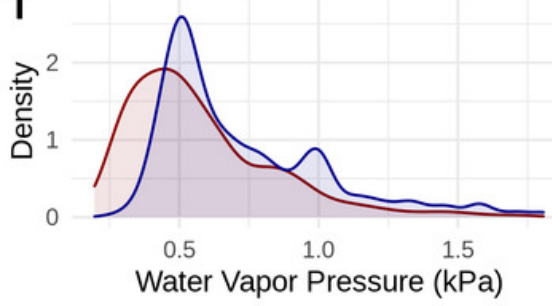

C 2020-03-30

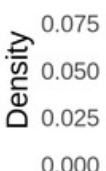

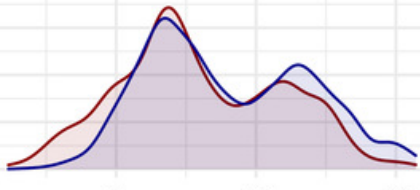

$\begin{array}{cc}0 & 10 \\ \text { Average } & \text { Temperature (C) }\end{array}$

F 0.100

高 0.075

0.000
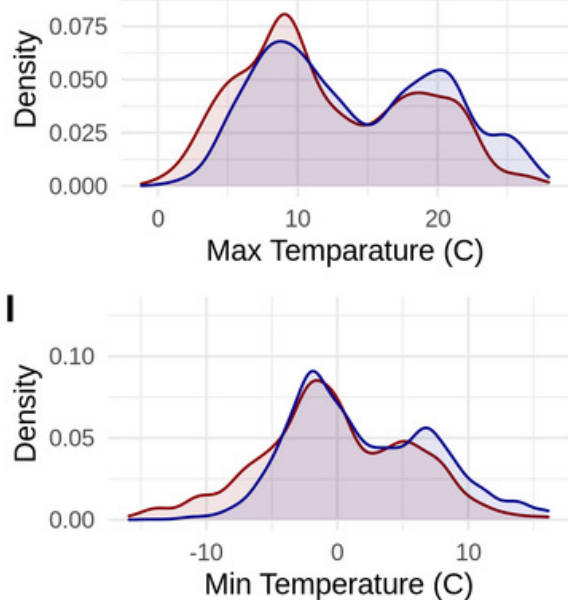

L 0.015

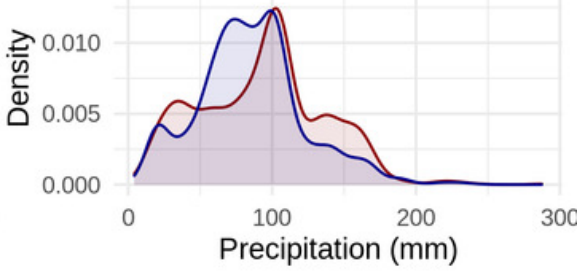

O $4 \mathrm{e}-04$

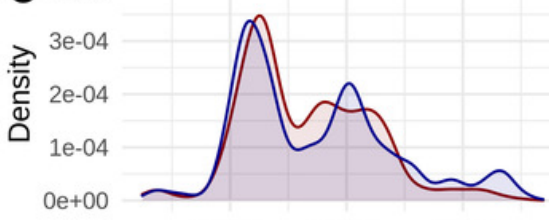

$1200015000 \quad 18000$ Solar Radiation (kJ m^-2 / day)

\section{R}

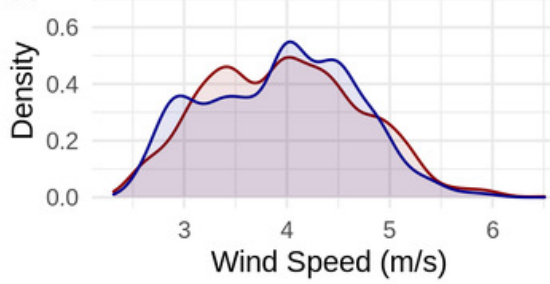

U

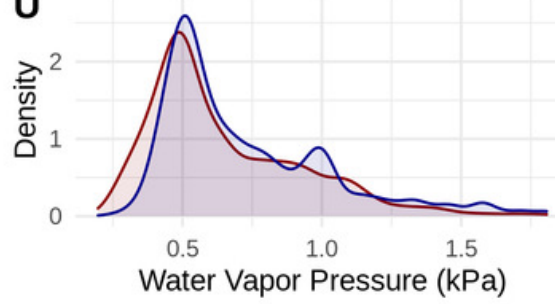


Figure 2

Figure 2. The relationship in the US between human population size and SARS-CoV-2 coronavirus cases

Figure 2. The relationship in the US between human population size and SARS-CoV-2 coronavirus cases, using (A) total viral cases and (B) population scaled viral cases. New York City, an outlying point, has been excluded for clearer visualization. 

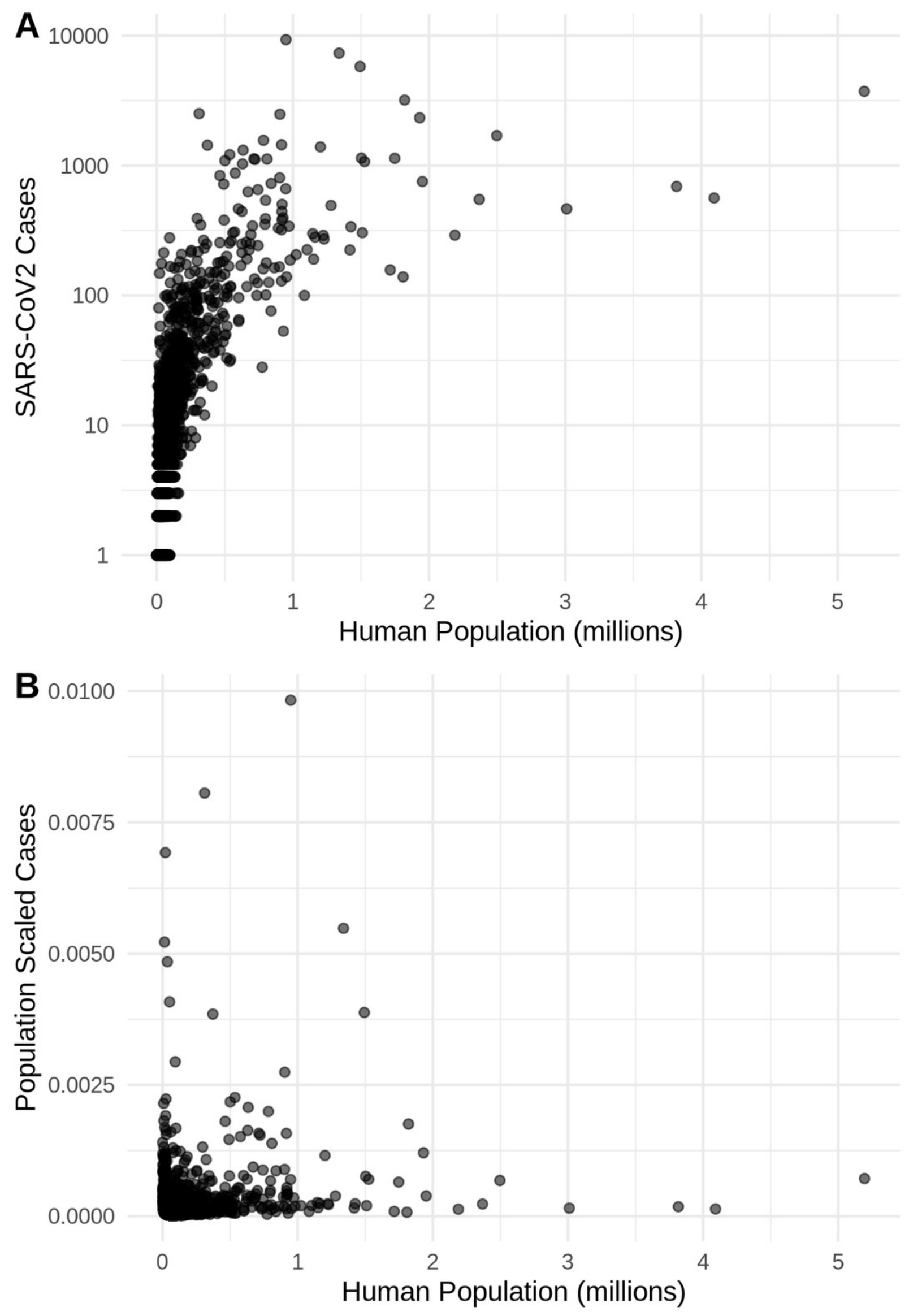
Figure 3

Figure 3. (A) Species distribution model of the SARS-CoV-2 coronavirus

Figure 3. (A) Species distribution model of the SARS-CoV-2 coronavirus (using population scaled data) for March 30, 2020. (B) Human population distribution model for the US from 2010. 
A

SARS-CoV2 Distribution Model

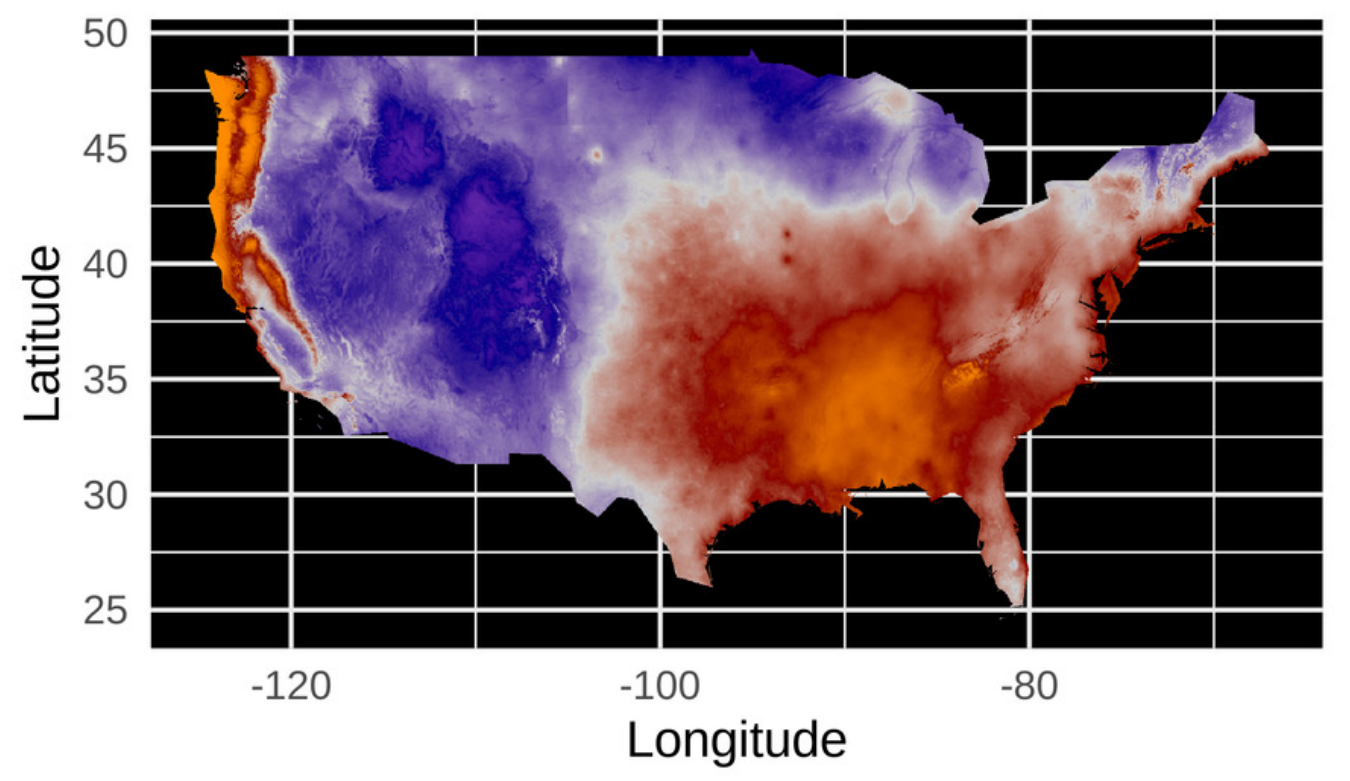

B

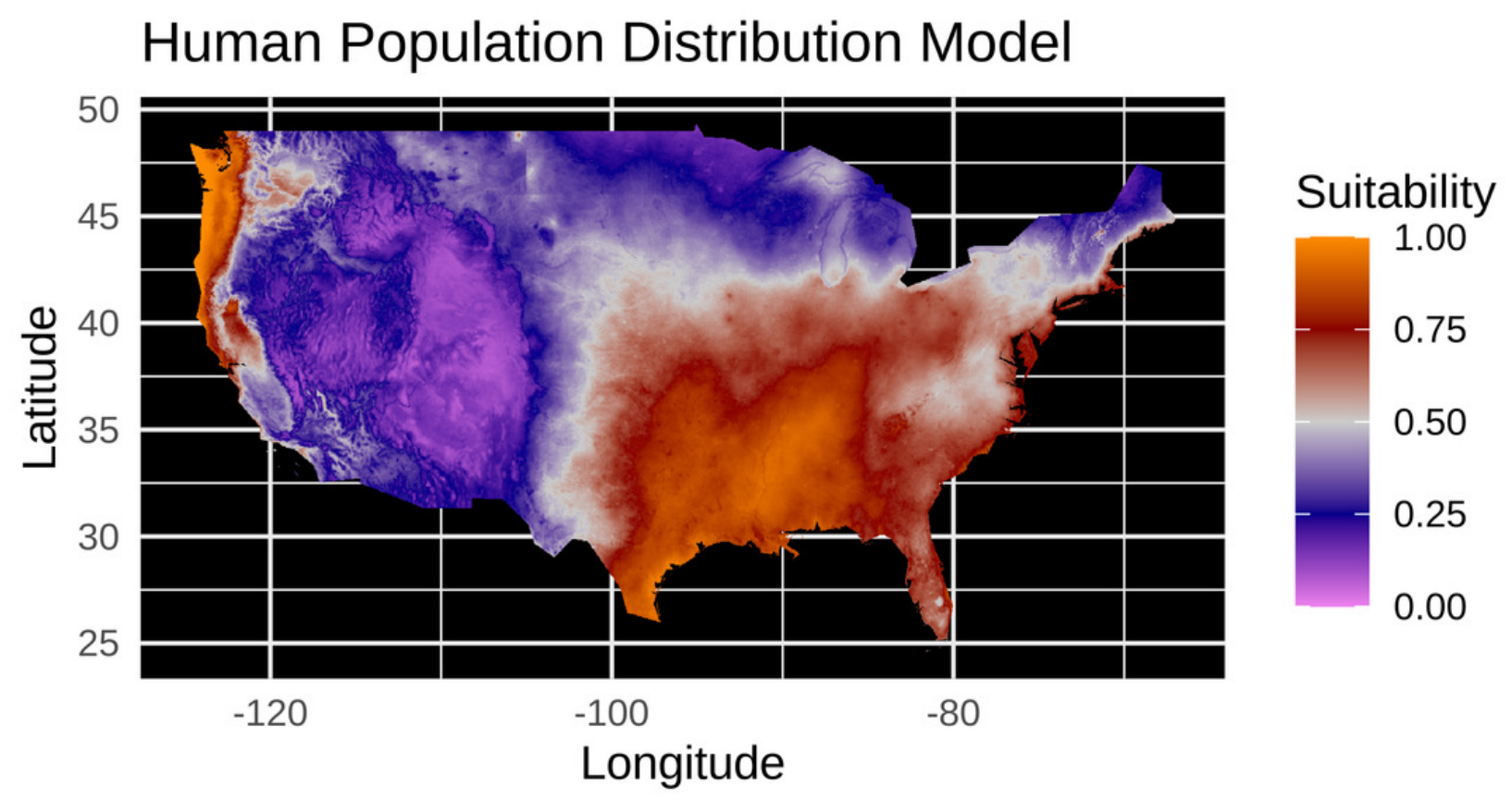




\section{Figure 4}

Figure 4. (A) Niche overlap and (B) similarity tests

Figure 4. (A) Niche overlap and (B) similarity tests for Maxent species distribution models built with population scaled SARS-CoV-2 coronavirus data compared to one built with human population density as occurrence data; actual model overlap indicated by a red marker in both plots. Significant $p$-values correspond to greater niche overlap or similarity than expected by random models. 


\section{Overlap}

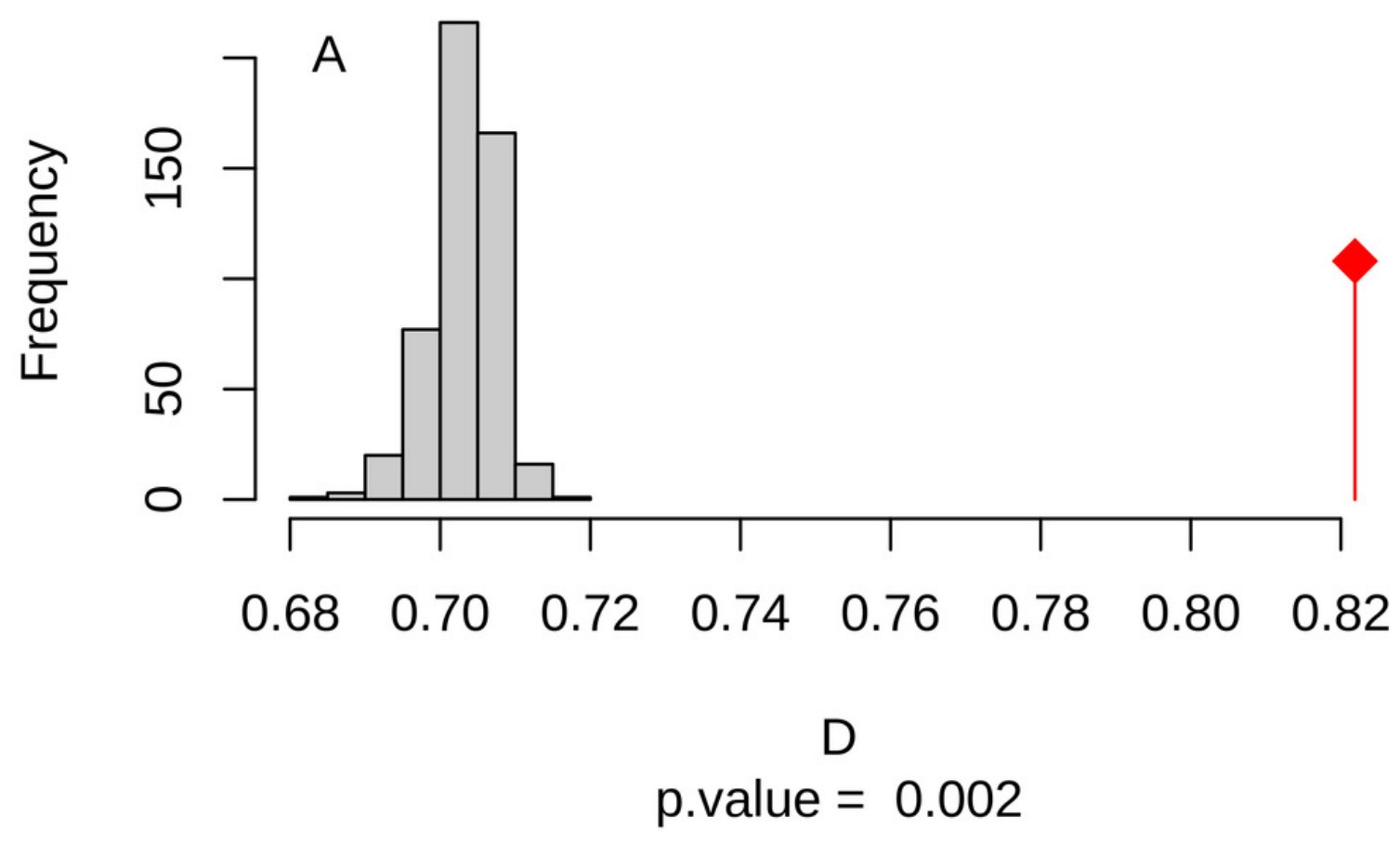

Similarity

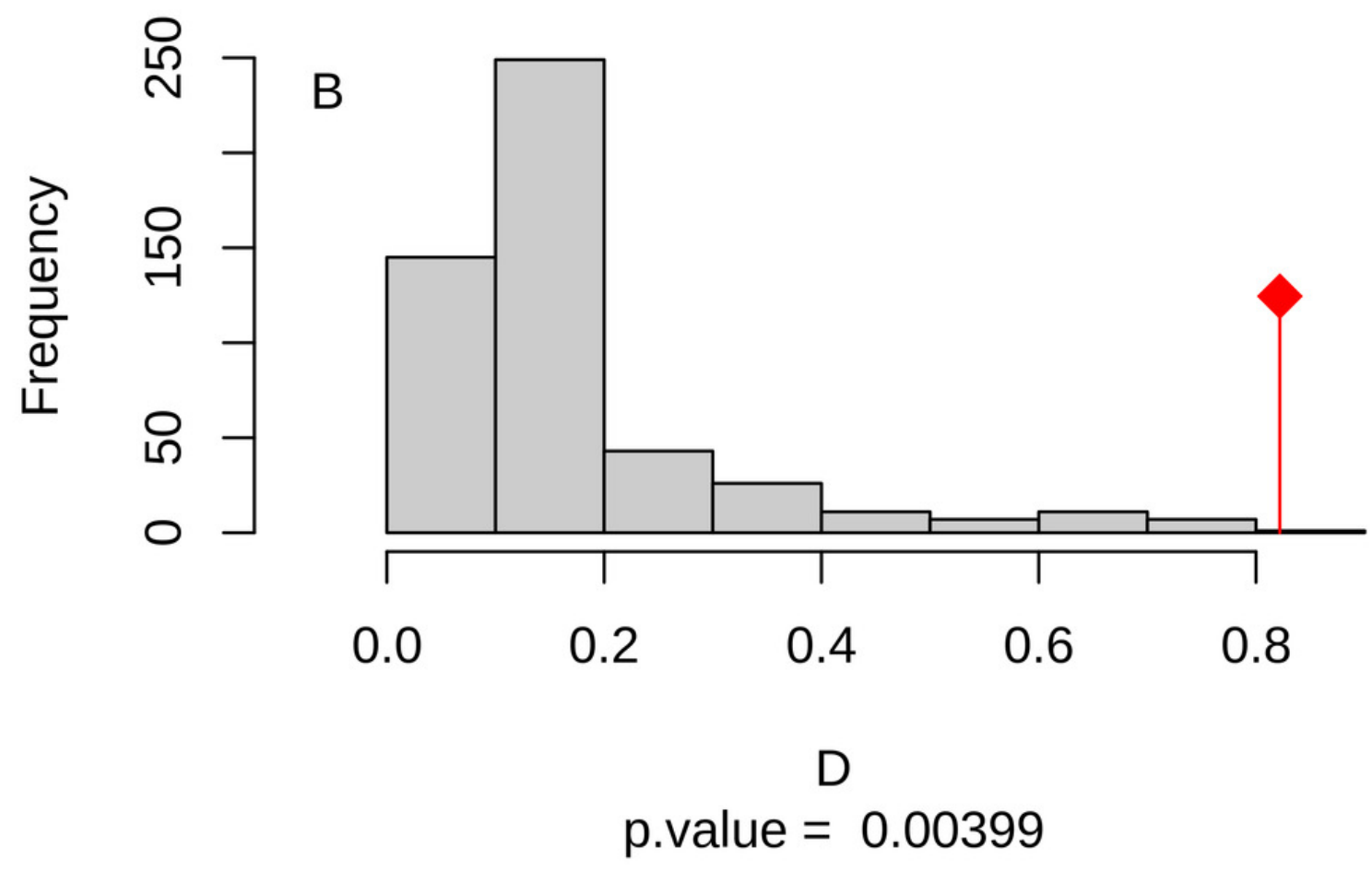

